\title{
Updated Probabilistic and Deterministic Seismic Hazard Analyses for the University of California, Berkeley and Lawrence Berkeley National Laboratory
}

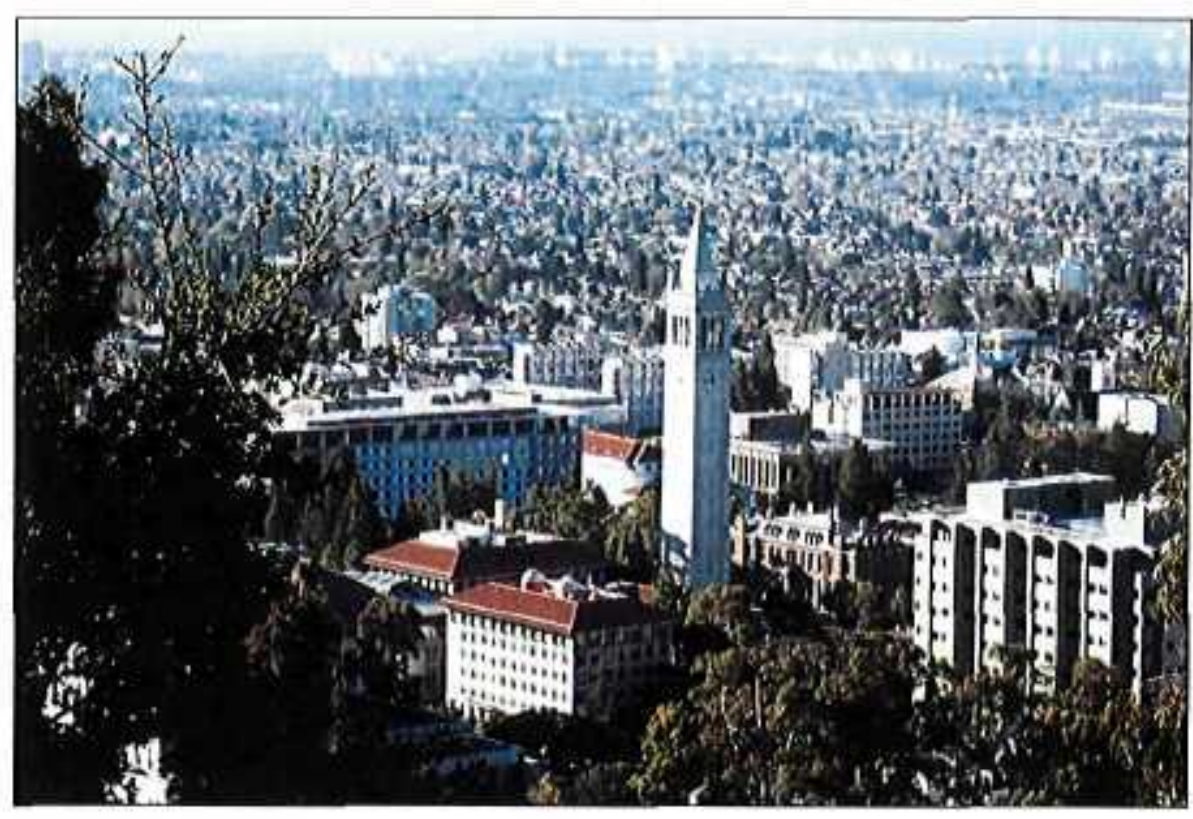

Prepared for

UCB Capital Projects

and

Lawrence Berkeley National Laboratory

14 May 2009

Prepared by

URS

Ivan Wong and Patricia Thomas

Seismic Hazards Group, URS Corporation

1333 Broadway, Suite 800, Oakland, California 94612

and

Paul Somerville

URS Corporation

566 El Dorado Street, Pasadena, CA 91101 


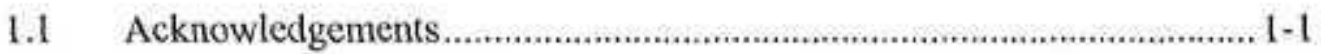

Section 2 Probabilistic Seismic Hazard Analyses Methodology …..........................................2-1

2.1 Seismic Source Characterization .................................................... 2-2

2.1.1 Source Geometry ................................................................. 2-2

2.1.2 Fault Recurrence ................................................................. 2-3

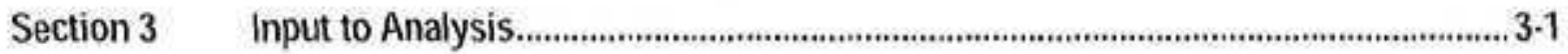

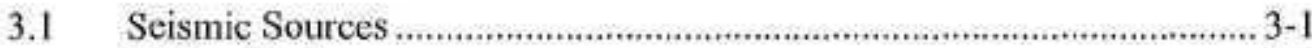

3.1.1 Faults................................................................................... 3-1

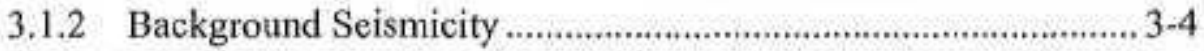

3.2 Ground Motion Attenuation Relationships.............................................. 3-4

Section $4 \quad$ Probabilistic Seismic Hazard Analysis Results ......................................................4-1

Section $5 \quad$ Topographic Amplification Effects ......................................................................... $5 \cdot 1$

Section $6 \quad$ Comparison With Other Spectra .............................................................................. 6-1

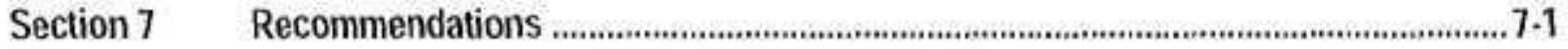

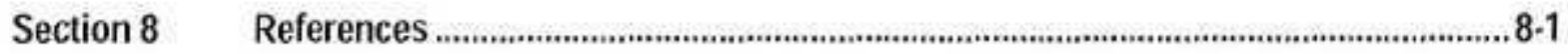

Table

1 Design Response Spectral Accelerations for UCB Thin Soil and Rock

2 Design Response Spectral Accelerations for LBNL

Figures

1 Historical Seismicity in the San Francisco Bay Region $(\mathbf{M} \geq 3.0), 1800$ to 2007

2 Active Faults in the Vicinity of the San Francisco Bay Region

3 Google Earth Image of the UCB and LBNL and the Hayward Fault

4 Seismic Hazard Curves for Peak Horizontal Acceleration at UCB Thin Soil Site

5 Seismic Hazard Curves for Peak Horizontal Acceleration at UCB Rock Site

6 Seismic Hazard Curves for Peak Horizontal Acceleration at LBNL Rock Site

7 Seismic Hazard Curves for 1.0 Sec Horizontal Spectral Acceleration at UCB Thin Soil Site

8 Seismic Hazard Curves for 1.0 Sec Horizontal Spectral Acceleration at UCB Rock Site 
9 Seismic Hazard Curves for $1.0 \mathrm{Sec}$ Horizontal Spectral Acceleration at LBNL Rock Site

10 Seismic Source Contributions to Peak Horizontal Acceleration Hazard at UCB Thin Soil Site

11 Seismic Source Contributions to 1,0 Sec Horizontal Spectral Acceleration Hazard at UCB Thin Soil Site

12 Magnitude and Distance Contributions to the Mean Peak Horizontal Acceleration Hazard at 475-Year Return Period at UCB Thin Soil Site

13 Magnitude and Distance Contributions to the Mean Peak Horizontal Acceleration Hazard at 2,475-Year Return Period at UCB Thin Soil Site

14 Magnitude and Distance Contributions to the Mean 1.0 Sec Horizontal Spectral Acceleration Hazard at 475-Year Return Period at UCB Thin Soil Site

15 Magnitude and Distance Contributions to the Mean $1.0 \mathrm{Sec}$ Horizontal Spectral Acceleration Hazard at 2,475-Year Return Period at UCB Thin Soil Site

16 Sensitivity of Mean Peak Horizontal Acceleration Hazard to Attenuation Relationships at UCB Thin Soil Site

17 Sensitivity of Mean $1.0 \mathrm{Sec}$ Horizontal Spectral Acceleration Hazard to Attenuation Relationships at UCB Thin Soil Site

18 Horizontal UHS for UCB Thin Soil Site

19 Horizontal UHS for UCB Rock Site

20 Horizontal UHS for LBNL Rock Site

21 Horizontal UHS at 475-Year Return Period for UCB Thin Soil, Rock and LBNL Rock

22 Topographic Gradients for LBNL

23 84th Percentile Deterministic Spectra for UCB Thin Soil Site

24 84th Percentile Deterministic Spectra for UCB Rock Site

25 Horizontal UHS for UCB Thin Soil Site Compared With Previous Study, CBC, and Deterministic Spectra

26 Horizontal UHS for UCB Rock Site Compared With Previous Study, CBC, and Deterministic Spectra 
The University of California, Berkeley (UCB) is situated in the seismically active San Francisco Bay region within the San Andreas fault system (Figure 1). The Hayward fault, which transects the campus, is estimated to have a probability of $27 \%$ of rupturing in an earthquake of moment magnitude (M) 6.7 or larger in the period 2002 to 2031 (Working Group on California Earthquake Probabilities [WGCEP], 2003) (Figures 2 and 3). UCB also will be subjected to strong ground shaking generated by future large events on numerous active faults within a distance of $50 \mathrm{~km}$ (Figure 1). This report presents the results of updated site-specific probabilistic and deterministic seismic hazard analyses for ground shaking of the UCB Campus and the Lawrence Berkeley National Laboratory (LBNL). Previous analyses of the Central Campus were performed by Geomatrix Consultants in 2000 and URS Corporation in 2003.

The purpose of probabilistic seismic hazard analyses (PSHA) is to assess the ground motion levels having specified frequencies of exceedance (return period). In this study, Uniform Hazard Spectra (UHS) at the frequencies of exceedance of $50 \%, 10 \%$, and $2 \%$ in 50 years and $10 \%$ in 100 years have been requested and are provided. These exceedance frequencies correspond to return periods of approximately $72,475,2,475$, and 949 years, respectively. The hazard has been evaluated for two average campus site conditions: thin alluvium over rock at the Central Campus and a rock site at the eastern edge of campus. Because LBNL is situated in the hills above UCB, potential topographic amplification also has been evaluated in this analysis.

In this study, the available geologic and seismologic data were used to evaluate and characterize (1) potential seismic sources, (2) the likelihood of earthquakes of various magnitudes occurring on those sources, and (3) the likelihood of the earthquakes producing ground motions exceeding a specified level. Two important aspects of these updated analyses are: (1) the results of the U.S. Geological Survey's (USGS) WGCEP (2003) and the California Geological Survey's efforts in developing the statewide probabilistic hazard maps (Cao et al., 2003) are used in the PSHA, and (2) the use of the recently developed Pacific Earthquake Engineering Research (PEER) Center's Next Generation of Attenuation (NGA) ground motion models.

The following report presents the seismic source characterization, the ground motion attenuation relationships used, the results of the PSHA for the Campus and LBNL, and the adjustment that could be made to the LBNL design spectrum due to topographic amplification.

\subsection{ACKNOWLEDGEMENTS}

Our appreciation to Craig Comartin for this support of this study and to Professors Jonathan Bray and Nick Sitar for their assistance and review of the report. Thanks to Melinda Lee and Fabia Terra for their help in preparing the report and to Keith Knudsen for his review.

This work was supported by the U.S. Department of Energy under Contract No. DE-AC02-05CH11231. 


\section{SE:HTONTWO Probahilistic Seismic Hazart Analyses Methodology}

The following is a description of the PSHA methodology used in this study. Inputs into the PSHAs are described in Section 3. The PSHA approach used in this study is based on the model developed principally by Cornell (1968). The occurrence of earthquakes on a fault is assumed to be a Poisson process. The Poisson model is widely used and is a reasonable assumption in regions where data are sufficient to provide only an estimate of average recurrence rate (Cornell, 1968). When there are sufficient data to permit a real-time estimate of the occurrence of earthquakes, the probability of exceeding a given value can be modeled as an equivalent Poisson process in which a variable average recurrence rate is assumed. The occurrence of ground motions at the site in excess of a specified level is also a Poisson process, if (1) the occurrence of earthquakes is a Poisson process, and (2) the probability that any one event will result in ground motions at the site in excess of a specified level is independent of the occurrence of other events.

The probability that a ground motion parameter " $Z$ " exceeds a specified value " $z$ " in a time period " $\mathrm{t}$ " is given by:

$$
\mathrm{p}(Z>z)=1-\mathrm{e}^{-v(z) \cdot t}
$$

where $v(z)$ is the annual mean number (or rate) of events in which $Z$ exceeds $z$. The assumption of a Poisson process for the number of events is not critical. This is because the mean number of events in time $t, v(z) \cdot t$ can be shown to be a close upper bound on the probability $p(Z>z)$ for small probabilities (less than 0.10 ) that generally are of interest for engineering applications. The annual mean number of events is obtained by summing the contributions from all sources, that is:

$$
v(z)=\sum_{n} v_{n}(z)
$$

where $v_{\mathrm{n}}(z)$ is the annual mean number (or rate) of events on source $\mathrm{n}$ for which $Z$ exceeds $z$ at the site. The parameter $v_{n}(z)$ is given by the expression:

$$
v_{n}(z)=\sum_{i j} \sum_{n}\left(m_{i}\right) \cdot p\left(R=r_{j} \mid m_{i}\right) \cdot p\left(Z>z \mid m_{i}, r_{j}\right)
$$

where:

$$
\begin{aligned}
& B_{n}\left(m_{i}\right)=\text { annual mean rate of recurrence of earthquakes of magnitude increment } m_{i} \text { on } \\
& \text { source n; } \\
& \mathrm{p}\left(\mathrm{R}=\mathrm{r}_{\mathrm{j}} \mid \mathrm{m}_{\mathrm{i}}\right) \quad \text { = probability that given the occurrence of an earthquake of magnitude } \mathrm{m}_{\mathrm{i}} \text { on }
\end{aligned}
$$

The PSHA calculations were made using the computer program HAZ38 developed by Norm Abrahamson. The program has been validated in the PEER Center-sponsored "Validation of PSHA Computer Programs" Project (Wong et al., 2004) and qualified for use by the U.S. Department of Energy. 


\subsection{SEISMIC SOURCE CHARACTERIZATION}

Two types of earthquake sources are characterized in these PSHAs: (1) fault sources; and (2) background earthquakes. Fault sources are modeled as three-dimensional fault surfaces and details of their behavior are incorporated into the source characterization. Background seismicity can be treated as areal source zones where earthquakes are assumed to occur randomly,

The geometric source parameters for faults include fault location, segmentation model, dip, and thickness of the seismogenic zone. The recurrence parameters include recurrence model, recurrence rate (slip rate or average recurrence interval for the maximum event), slope of the recurrence curve ( $b$-value), and maximum magnitude. Clearly, the geometry and recurrence are not totally independent. For example, if a fault is modeled with several small segments instead of large segments, the maximum magnitude is lower, and a given slip rate requires many more small earthquakes to accommodate a cumulative seismic moment. For areal source zones, only the area, seismogenic thickness, maximum magnitude, and recurrence parameters (based on the historical earthquake record) need to be defined.

Uncertainties in the source parameters are included in the PSHAs using logic trees. In this procedure, values of the source parameters are represented by the branches of logic trees with weights that define the distribution of values. In general, three values for each parameter were weighted and used in the analysis. Statistical analyses by Keefer and Bodily (1983) indicate that a threc-point distribution of 5 th, 50 th, and 95 th percentiles weighted $0.185,0.63$, and 0.185 (rounded to $0.2,0.6$, and 0.2 ), respectively, is the best discrete approximation of a continuous distribution. Alternatively, they found that the $10 \mathrm{th}, 50$ th, and 90 th percentiles weighted $0.3,0.4$, and 0.3 , respectively, can be used when limited available data make it difficult to determine the extreme tails (i.e., the 5 th and 95 th percentiles) of a distribution. Note that the weights associated with the percentiles are not equivalent to probabilities for these values, but rather are weights assigned to define the distribution. We generally applied these guidelines in developing distributions for seismic source parameters with continuous distributions (e.g., $M_{\max }$, fault dip, slip rate or recurrence) unless the available data suggested otherwise. Estimating the 5 th, 95 th, or even 50th percentiles is typically challenging and involves subjective judgment given limited available data.

\subsubsection{Source Geometry}

In the PSHAs, it is assumed that earthquakes of a certain magnitude may occur randomly along the length of a given fault or segment. The distance from an earthquake to the site is dependent on the source geometry, the size and shape of the rupture on the fault plane, and the likelihood of the earthquake occurring at different points along the fault length. The distance to the fault is defined to be consistent with the specific attenuation relationship used to calculate the ground motions. The distance, therefore, is dependent on both the dip and depth of the fault planc, and a separate distance function is calculated for each geometry and each attenuation relationship. The size and shape of the rupture on the fault plane are dependent on the magnitude of the earthquake, with larger events rupturing longer and wider portions of the fault plane. For a given magnitude, the associated rupture surface is uniformly distributed along the fault length and width. Ruptures are constrained to occur entirely on the defined fault plane. We modeled the 
rupture dimensions following the magnitude-rupture area and magnitude-rupture width relationships of Wells and Coppersmith (1994).

\subsubsection{Fault Recurrence}

The recurrence relationships for the faults are modeled using the exponentially truncated Gutenberg-Richter, characteristic earthquake, and the maximum magnitude recurrence models. These models are weighted to represent our judgment on their applicability to the sources. For the areal source zones, only an exponential recurrence relationship is assumed appropriate.

We have used the general approach of Molnar (1979) and Anderson (1979) to arrive at the recurrence for the exponentially truncated model. The number of events excecding a given magnitude, $N(m)$, for the truncated exponential relationship is

$$
N(m)=\alpha\left(m^{0}\right) \frac{10^{b\left(m-m^{2}\right)}-10^{-b\left(m^{2}-m^{2}\right)}}{1-10^{-b\left(m^{2}-m^{2}\right)}}
$$

where $\alpha\left(m^{\circ}\right)$ is the annual frequency of occurrence of earthquake greater than the minimum magnitude, $m^{0} ; b$ is the Gutenberg-Richter parameter defining the slope of the recurrence curve; and $m^{\prime \prime}$ is the upper-bound magnitude event that can occur on the source. A $m^{\circ}$ of $\mathbf{M} 5.0$ was used for the hazard calculations because smaller events are not considered likely to produce ground motions with sufficient energy to damage well-designed structures.

We have included the model where faults rupture with a "characteristic" magnitude on specific segments; this model is described by Aki (1983) and Schwartz and Coppersmith (1984). For the characteristic model, we have used the numerical model of Youngs and Coppersmith (1985). In the characteristic model, the number of events exceeding a given magnitude is the sum of the characteristic events and the non-characteristic events. The characteristic events are distributed uniformly over \pm 0.25 magnitude unit around the characteristic magnitude and the remainder of the moment rate is distributed exponentially using the above equation with a maximum magnitude one unit lower than the characteristic magnitude (Youngs and Coppersmith, 1985).

The maximum magnitude model can be regarded as an extreme version of the characteristic model. We adopted the model proposed by Wesnousky (1986) in which there is no exponential portion of the recurrence curve, i.e., no events can occur between the minimum magnitude of $\mathbf{M}$ 5.0 and the distribution about the maximum magnitude.

The recurrence rates for the fault sources are defined by either the slip rate or the average return time for the maximum or characteristic event and the recurrence $b$-value. The slip rate is used to calculate the moment rate on the fault using the following equation defining the seismic moment:

$$
\mathrm{M}_{\mathrm{o}}=\mu \mathrm{AD}
$$

where $\mathrm{M}_{0}$ is the seismic moment, $\mu$ is the shear modulus, $\mathrm{A}$ is the area of the rupture plane, and $\mathrm{D}$ is the slip on the plane. Dividing both sides of the equation by time results in the moment rate as a function of slip rate:

$$
\dot{M}_{\mathrm{o}}=\mu \mathrm{AS}
$$


where $\dot{M}_{a}$ is the moment rate and $\mathrm{S}$ is the slip rate. Mo has been related to moment magnitude, M, by Hanks and Kanamori (1979):

$$
\mathbf{M}=2 / 3 \log M_{0}-10.7
$$

Using this relationship and the relative frequency of different magnitude events from the recurrence model, the slip rate can be used to estimate the absolute frequency of different magnitude events.

The average return time for the characteristic or maximum magnitude event defines the high magnitude (low likelihood) end of the recurrence curve. When combined with the relative frequency of different magnitude events from the recurrence model, the recurrence curve is established. 
The following section describes the characterization of the seismic sources considered in the seismic hazard analyses and the empirical ground motion attenuation relationships selected and used.

\subsection{SEISMIC SOURCES}

Seismic source characterization is concerned with three fundamental elements: (1) the identification location and geometry of significant sources of earthquakes; (2) the maximum size of the earthquakes associated with these sources; and (3) in the probabilistic analysis, the rate at which they occur. The source parameters for the significant faults in the site region (generally within about $100 \mathrm{~km}$ ) were characterized for input into the hazard analyses. Areal source zones representing background earthquakes also were characterized and used in the probabilistic analysis.

\subsubsection{Faults}

Based on our review of published and unpublished data, the active and potentially active seismogenic faults shown on Figure 2 are considered to be seismic sources significant to UCB for strong ground shaking. A description of the most significant source, the Hayward-Rodgers Creek faults, is given in the next section.

The guiding philosophy for characterizing seismic sources in this study is the following. The fundamental seismic source characterization came from studies by the USGS Working Group on Northern California Earthquake Potential (WGNCEP, 1996), the USGS Working Group on California Earthquake Probabilities (WGCEP, 2003) and the California Geological Survey's seismic source model used in the USGS National Hazard Maps (Cao et al., 2003). This characterization was updated and revised based on recent research (Wong et al, 2008).

Figures 2 and 3 show the locations of the faults relative to UCB. Faults were included that were judged to be at least potentially active and that would potentially contribute to the probabilistic hazard because of their maximum earthquakes and/or proximity to the damsite.

In this PSHA, all faults are modeled as single, independent, planar sources extending the full extent of the seismogenic crust. Thus, fault dips are averages estimated over the seismogenic crust. For all seismic sources, the seismogenic crust was assumed to be $15 \pm 3 \mathrm{~km}$ thick based on well-located contemporary seismicity (e.g., Oppenheimer and MacGregor-Scott, 1992).

A lack of reliable paleoseismic data means that the recurrence rates for many of the faults within the San Francisco Bay region are either poorly understood or unknown. Fault activity is therefore expressed as an average annual slip rate (in $\mathrm{mm} / \mathrm{yr}$ ) rather than recurrence intervals. The uncertainty in the slip rates and the other input parameters are accommodated in the probabilistic hazard through the use of logic trees.

Uncertainties in determining recurrence models can significantly impact the hazard analysis. We considered truncated exponential, maximum-magnitude, and characteristic recurrence models, with various weights depending on the source geometry and type of rupture model. These models and their implementation into the calculations were discussed in Section 2. Observations of historical seismicity and paleoseismic investigations along faults in the western U.S. (e.g., San Andreas fault) suggest that characteristic behavior is more likely for individual faults (Schwartz 
and Coppersmith, 1984). Therefore, we generally favored the characteristic model for all fault sources (weight of 0.70 ) while the maximum magnitude model was weighted 0.30 .

\subsubsection{Hayward-Rodgers Creek Fault System}

The Hayward fault extends for $100 \mathrm{~km}$ from the area of Mount Misery, east of San Jose, to Point Pinole on San Pablo Bay (Figure 2). At Point Pinole, the Hayward fault runs into San Pablo Bay. The northern continuation of this fault system is the Rodgers Creek fault (Figure 2). The two faults are separated by a 5-km-wide right step beneath San Pablo Bay. Systematic rightlateral geomorphic offsets and creep offset of cultural features have been well documented along the entire length of the fault (Lienkacmper, 1992). The last major earthquake on the Hayward fault, in October 1868, occurred along the southern segment of the fault (Figure 1). This M 6.8 event caused toppling of buildings in Hayward and other localities within about $5 \mathrm{~km}$ of the fault. The surface rupture associated with this earthquake is thought to have extended for approximately $30 \mathrm{~km}$, from Warm Springs to San Leandro, with a maximum reported displacement of about $1 \mathrm{~m}$. The Hayward fault is considered the most likely source of the next major earthquake in the San Francisco Bay area (WGCEP, 2003). As well as undergoing displacement in earthquake ruptures, the Hayward fault also moves by aseismic creep. Measurements along the fault over the last two decades show that the creep rate is 5 to $9 \mathrm{~mm} / \mathrm{yr}$ (Lienkaemper and Galehouse, 1997).

Recent research of historical documents has led to the conclusion that an earthquake in 1836, previously thought to have occurred on the northern Hayward fault, occurred elsewhere (Toppozada and Borchardt, 1998), thereby increasing the time since the last earthquake on this segment of the fault. Paleoseismic trenching along the northern Hayward fault indicates that the last surface rupturing earthquake along this part of the fault was sometime between 1626 and 1724 (Lienkaemper et al,, 1999). This study also indicated at least four surface-rupturing earthquakes in the last 2,250 years. The WGCEP (2003) assigns maximum earthquakes of $\mathbf{M} 6.5$ and 6.7, and recurrence intervals of 387 and 371 years, for the northern and southern segments of the Hayward fault, respectively. Recent studies by Lienkaemper and Williams (2007) indicate that there have been 10 earthquakes along the southern Hayward fault since about 170 A.D. resulting in an average recurrence interval of 170 years. The last 5 events have an average recurrence interval of $140 \pm 50$ years. It has been 141 years since the 1868 event.

Rupture of the entire fault zone would generate an earthquake of $\mathbf{M}$ 7.0. The WGCEP (2003) considers the Hayward-Rodgers Creek fault system the most likely source of the next $\mathbf{M} 6.7$ or larger carthquake in the Bay Area, with a 27 percent probability of occurring in the time period 2002 to 2031. Their model also incorporates a scenario where the Hayward fault ruptures along with the Rodgers Creek fault. Rupture of the entire length of both faults would generate a maximum earthquake of $\mathbf{M} 7.3$. Rupture of the Rodgers Creek fault and the northern segment of the Hayward fault would generate a maximum event of M 7.1.

The Rodgers Creek fault is $44 \mathrm{~km}$ long (Figure 2) and its geomorphic expression is similar to that of the Hayward fault. At its northern end, the Rodgers Creek fault is separated from the Healdsburg fault by a 3-km-wide right step, and separated from the Maacama fault by a $10-\mathrm{km}-$ wide right step (Wagner and Bortugno, 1982). Holocene activity along the Rodgers Creek is indicated by a series of fault scarps in Holocene deposits, side-hill benches, right-laterally offset streams, and closed linear depressions. Microseismicity is nearly absent along much of the 
length of the fault suggesting that it is a seismic gap and the site of an impending earthquake (Wong, 1991). Paleoseismic investigations by Schwartz et al. (1992) revealed three events in 925 to 1,000 years. This gives a preferred recurrence of 230 years for a maximum earthquake of M 7.0. The most recent earthquake occurred on the fault sometime between 1438 to 1654 AD (Schwartz et al., 1992). The calculated slip rate for the Rodgers Creek fault is $9 \pm 2 \mathrm{~mm} / \mathrm{yr}$.

\subsubsection{Fault Creep (Aseismic Slip) and the R Factor}

Some faults or sections of faults are thought to move in a continuous aseismic manner, i.e., they slip without generating large earthquakes. The San Juan Bautista segment of the San Andreas fault is the best example of a creeping fault segment. Fault creep has been documented along portions of the Hayward, Calaveras, San Andreas, and Concord faults in the San Francisco Bay region. However, fault crecp is still poorly understood. The primary indicator of the presence of aseismic slip at depth is the observation of surficial fault creep (e.g., Galehouse, 1995). If surficial fault creep is not observed, there is little reason to suspect that it is a significant fault attribute at seismogenic depths. If surficial fault creep is observed, aseismic slip may extend to seismogenic depths beneath that section of that fault and can account for a significant portion of the slip rate available for earthquake generation (WGCEP, 2003).

Between 3 and $10 \mathrm{~mm} /$ year of fault creep has been measured along the trace of the southern segment of the Hayward fault, where the Hayward fault slipped in the M 6.8 earthquake of 21 October 1868 (WGNCEP, 1996). This amount of fault creep on the southern Hayward fault cannot extend through the seismogenic depth range. In fact, the inferred depth extent of creep varies along strike from $4 \mathrm{~km}$ to the bottom of the seismogenic zone (Simpson et al., 2001). Models require locked patches under the central portion of the Hayward fault, consistent with the earthquake in 1868, but the geometry and extent of locking under the north and south ends of the Hayward fault depend critically on assumptions of fault geometry. Bürgmann et al. (2000) suggested from InSAR (synthetic aperture radar interferometry) data and the presence of repeating microearthquakes that a $20-\mathrm{km}$-long section of the northern Hayward fault may be creeping at all depths, precluding the initiation of any large earthquake under that section of fault. Simpson et al.'s (2001) models contain 1.4 to 1.7 times more stored moment along this stretch of the Hayward fault than does the model of Bürgmann et al. (2000). There is considerable uncertainty regarding the relative importance of aseismic slip on the Hayward fault, and on the other faults characterized by WGCEP (2003).

WGCEP (2003) accounted for aseismic slip through a seismic slip factor $R$ that varies from 0 , where all slip rate is accounted for by aseismic slip, to 1.0, where all of the slip rate is accounted for by earthquakes. Regional tectonic models based on geodetic observations collected in the San Francisco Bay region in the last few decades are the primary basis for determining the $R$ values.

$R$ is used to reduce the potential rupture area of each fault. Since earthquake magnitude is calculated from the area, $R$ scales $\mathbf{M}$. Less frequent events with larger $\mathbf{M}$ are necessary to satisfy the geologic slip rate, so the average recurrence time $\mathrm{T}$ decreases with decreasing $R$. That is, a decrease in $R$ on a fault segment decreases the mean magnitude and the mean recurrence time for segment-rupturing earthquakes. However, this effect is not known with certainty. The effect of $R$ may be to increase the mean recurrence time (i.e., with fault creep) without a change to the expected magnitude. 
Given the recent development of the concept of the $R$-factor and the fact that it is not universally accepted at this time, its use in seismic hazard evaluations is controversial. The adoption of $R$ factors in PSHAs results in the incorporation of $R$-adjusted maximum magnitudes from WGCEP (2003), which will yield ground motions higher than has been traditionally estimated without them. We have adopted the WGCEP (2003) maximum magnitudes in these PSHAs but we also include a larger epistemic uncertainty of \pm 0.3 about the mean values to address the large uncertainty in the R-factors.

\subsubsection{Background Seismicity}

To account for the hazard from background (floating or random) earthquakes in the probabilistic seismic hazard analysis that are not associated with known or mapped faults, regional seismic source zones were used. In most of the western U.S., the maximum magnitude of earthquakes not associated with known faults usually ranges from M 6 to $61 / 2$. Repeated events larger than these magnitudes generally produce recognizable fault-or-fold related features at the earth's surface (e.g., dePolo, 1994). An example of a background earthquake is the 1986 M 5.7 Mt. Lewis earthquake that occurred east of San Jose.

Earthquake recurrence estimates of the background seismicity in each seismic source zone are required. The site region was divided into two regional seismic source zones: the Coast Ranges and Central Valley. The recurrence parameters for the Coast Ranges source zone were adopted from Youngs et al. (1992). They calculated values for background earthquakes based on the historical seismicity record after removing earthquakes within $10-\mathrm{km}$-wide corridors along each of the major faults. The recurrence values for the Central Valley zone were adopted from URS Corporation (2001). The a-values have been normalized per year and per $\mathrm{km}^{2}$. Maximum earthquakes for both zones of M $6.5 \pm 0.3$ were used in the probabilistic analysis.

\section{Recurrence Parameters}

\begin{tabular}{|c|c|c|}
\hline Source Zone & b & a \\
\hline Coast Ranges & 0.72 & -3.68 \\
\hline Central Valley & 1.14 & -0.73 \\
\hline
\end{tabular}

\subsection{GROUND MOTION ATTENUATION RELATIONSHIPS}

To characterize the attenuation of ground motions in the probabilistic analysis, we have used recently developed empirical attenuation relationships appropriate for tectonically active regions such as the western U.S. These new attenuation relationships, developed as part of the NGA Project sponsored by the PEER Center Lifelines Program, have been published in the journal Earthquake Spectra. The NGA models have a substantially better scientific basis than prior relationships (e.g., Abrahamson and Silva, 1997) because they are developed through the efforts of five selected attenuation relationship developer teams working in a highly interactive process with other researchers who have: (a) developed an expanded and improved database of strong ground motion recordings and supporting information on the causative earthquakes, the sourceto-site travel path characteristics, and the site and structure conditions at ground motion recording stations; (b) conducted research to provide improved understanding of the effects of various parameters and effects on ground motions that are used to constrain attenuation models; 
and (c) developed improved statistical methods to develop attenuation relationships including uncertainty quantification. The relationships have benefited greatly from a large amount of new strong motion data from large earthquakes $(M>7)$ at close-in distances $(<25 \mathrm{~km})$. Data include records from the 1999 M 7.6 Chi Chi, Taiwan, 1999 M 7.4 Kocaeli, Turkey, and 2002 M 7.9 Denali, Alaska earthquakes. Review of the NGA relationships indicate that, in general, ground motions particularly at short-periods (e.g., peak acceleration) are significantly reduced particularly for very large magnitudes $(\mathbf{M} \geq 7.5)$ compared to current relationships. The relationships by Chiou and Youngs (2008), Campbell and Bozorgnia (2008), Abrahamson and Silva (2008), Boore and Atkinson (2008), and Idriss (2008) were used in the PSHAs. The relationships were reviewed and weighted equally in the PSHAs.

$\mathrm{A} \mathrm{V}_{\mathrm{S}} 30$ (shear-wave velocity in the top $30 \mathrm{~m}$ ) of $600 \mathrm{~m} / \mathrm{sec}$ was adopted for the Central Campus, $900 \mathrm{~m} / \mathrm{sec}$ for a rock site at the Campus eastern edge, and $566 \mathrm{~m} / \mathrm{sec}$ for the LBNL. The $\mathrm{V}_{\mathrm{S}} 30$ for the rock site was adopted from Geomatrix Consultants (2000). The LBNL V 30 is derived from Wills and Clahan (2006) assuming rock of the Great Valley sequence. The Idriss (2008) relationship does not have $\mathrm{V}_{\mathrm{S}} 30$ as a variable but it is appropriate for a rock site condition. It was used for all three site conditions.

For the Central Campus, we have derived the $V_{\mathrm{S}} 30$ value by assuming an average thickness of alluvium across campus of $10.7 \mathrm{~m}$ (35 ft) with a $V_{\mathrm{S}} 30$ of $370 \mathrm{~m} / \mathrm{sec}$ (Geomatrix Consultants, 2000 ) and the underlying Franciscan complex rock with a $V_{\mathrm{S}} 30$ of $715 \mathrm{~m} / \mathrm{sec}$ from Wills and Clanahan (2006). This "thin soil" condition is not well represented in the strong motion recordings in the NGA database. The resulting $\mathrm{V}_{\mathrm{S}} 30$ of $600 \mathrm{~m} / \mathrm{sec}$ also is misleading because such a value is more indicative of a "firm" rock site. Hence the hazard calculated using a V 30 of $600 \mathrm{~m} / \mathrm{sec}$ could be underestimated using the NGA models at moderate to high frequencies. However, the hazard has been calculated in this study for an "average" site condition and deviations are cxpected across campus.

To incorporate the variability in $\mathrm{V}_{\mathrm{S}} 30$ across the campus due to varying thickness of the alluvium

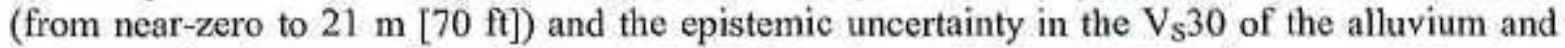
rock, we also have run the soil hazard for $V_{\mathrm{S}} 30$ values of 500 and $700 \mathrm{~m} / \mathrm{sec}$, or $\pm 100 \mathrm{~m} / \mathrm{sec}$. The $V_{\mathrm{S}} 30$ uncertainty of $100 \mathrm{~m} / \mathrm{sec}$ was estimated by varying the alluvium thickness to see its impact on $V_{s} 30$. Similarly, for the campus site and LBNL, we have varied the $V_{s} 30 \pm 100 \mathrm{~m} / \mathrm{sec}$ based on the uncertainties in $V_{\mathbb{S}} 30$ calculated by Wills and Clahan (2006).

Average fault rupture directivity was included in the PSHA using the model by Somerville et al. (1997) as modified by Abrahamson (2000). In the PSHA, the hypocenter is randomized along the length of the fault given the lack of a priori knowledge of the rupture initiation. The use of fault-normal rupture directivity is currently believed to be too conservative, based on studies associated with the NGA Project, and so average fault directivity is incorporated into the hazard results.

Other input parameters include $Z_{2.5}$, the depth to the $V_{S}$ of $2.5 \mathrm{~km} / \mathrm{sec}$ (a proxy for basin effects), which is only used in one model, Campbell and Bozorgnia (2008). We have used the default value of $2.0 \mathrm{~km}$ as recommended by the authors in lieu of site-specific data. Abrahamson and Silva (2008) and Chiou and Youngs (2008) used $Z_{1.0}$, the depth to the $V_{S}$ of $1.0 \mathrm{~km} / \mathrm{sec}$. We have used the relations provided by the developers to estimate $Z_{1.0}$ based on the $V_{\mathrm{S}} 30$ of the site. Other parameters such as depth to the top of rupture (zero for all surficial faults unless specified 
otherwise), dip angle, rupture width, and aspect ratio were specified for each fault or calculated within the PSHA code. 
The results of the PSHAs of UCB and LBNL are presented in terms of ground motion as a function of annual exceedance probability. This probability is the reciprocal of the average return period. We have computed the hazard at central locations at both sites. The results shown are for the best estimate $V_{\mathrm{S}} 30$ values. Figures 4 to 6 show the mean, median, 5 th, 15 th, 85 th, and 95th percentile hazard curves for peak horizontal ground acceleration (PGA). These fractiles indicate the range of epistemic uncertainty about the mean hazard. The $1.0 \mathrm{sec}$ horizontal spectral acceleration (SA) hazard is shown on Figures 7 to 9. At a return period of 2,500 years, there is a factor of more than 1.5 difference between the 5th and 95th percentile values at UCB soil site (Figure 4).

The probabilistic spectral acceleration values are listed in Table 1 for the return periods of 72 , 475,949 , and 2,475 years for both UCB thin soil and rock. Spectral accelerations for LBNL are given in Table 2. The hazard is very high because the sites are located adjacent to the Hayward fault.

The contributions of the various seismic sources to the mean PGA hazard at UCB thin soil site are shown on Figure 10. The results are nearly identical for UCB rock site and LBNL so only the UCB results are shown. The Hayward fault totally dominates the short-period hazard as expected. The same is true for long-period ground motions, e.g., $1.0 \mathrm{sec}$ spectral acceleration (Figure 11). The San Andreas fault contributes to the hazard at significantly lower levels.

By deaggregating the mean PGA and $1.0 \mathrm{sec}$ horizontal SA hazard by magnitude and distance bins, Figures 12 to 15 illustrate the contributions by events. At 475 and 2,475-year return periods, the PGA hazard is dominated by events in the magnitude range of $\mathbf{M} 6.0$ to 7.5 at distances of less than $5 \mathrm{~km}$ coming from the Hayward fault (Figures 12 and 13). At $1.0 \mathrm{sec} \mathrm{SA}$, the same pattern holds (Figures 14 and 15).

The sensitivity of the PGA and $1.0 \mathrm{sec}$ SA hazard to different attenuation relationships is shown on Figures 16 and 17. Each hazard curve is calculated using only that respective attenuation relationship. The mean hazard curves also are shown. At PGA the Campbell and Bozorgnia (2008) gives slightly lower hazard while the Idriss (2008) relationship gives slightly higher hazard results (Figure 16). At $1.0 \mathrm{sec} \mathrm{SA}$, the Abrahamson and Silva (2008) gives the lowest hazard while Idriss (2008) and Chiou and Youngs (2008) give the highest hazard. These results are a measure of the epistemic uncertainty.

UHS for UCB thin soil and rock and LBNL for the four specified return periods are computed for the three values of $V_{S} 30$. Because of the lack of site-specific $V_{S}$ data and the spatial variability across the campus and LBNL areas, any design spectrum for the campus should account for this uncertainty. The spectra for each site, $V_{\mathrm{S}} 30$ and return period are shown in Figures 18 to 20.

Figure 21 compares the 475 -year return period design spectra for all three sites. 
The LBNL site is located on a ridge, as shown in the topographic map in Figure 22. The site is shown by a red triangle, and the blue lines indicate profiles whose slopes are expressed in percentages of the ratio of height $(\mathrm{H})$ to length $(\mathrm{L})$; these values range from 22 to $43 \%$. According to the Eurocode 8 (2003), these values of slope are expected to produce a broadband amplification of $20 \%$ in ground motion level.

A review of topographic amplification effects and their treatment in Eurocode 8 is provided by Pagliaroli et al. (2006). In practice, we expect topographic amplification to be period-dependent, starting at a value of unity (no amplification) at long periods, ramping up to a constant factor over a period band that is related to the dimensions of the slope and the shear wave velocity, and maintaining that level at shorter periods. The period band of the ramp would be approximately 0.3 to 0.7 seconds if there were simple 2D topography at the site. However, the topography is quite complex, and so this approach to estimating a period-dependent topographic amplification factor is unreliable. Numerical modeling of seismic wave interaction with the 3D topography of the site, beyond the scope of this project, would be required to obtain a reliable estimate of the period-dependent topographic amplification effect at the site. 
Median and 84th percentile deterministic spectra for a maximum earthquake of $\mathbf{M} 6.9$ on the Hayward fault have been calculated for both a rock and soil site condition using the same NGA models used in the PSHA (Figures 23 and 24). The rupture distance for the soil site was $0.5 \mathrm{~km}$ and $0.2 \mathrm{~km}$ for the rock site; the latter being closer to the fault. Figures 25 and 26 compare the deterministic spectra with the 475-year return period campus soil and rock design spectra developed in this study, the previous design spectra for the Central Campus (URS, 2003), and the 2007 CBC spectra (Class C and B, respectively). All spectra with the exception of the CBC spectra have been adjusted for average fault rupture directivity.

The 2003 spectrum for the Central Campus was developed using pre-NGA attenuation relations for rock/shallow stiff soil. As shown, the 2003 design spectrum and this study's spectrum for soil are quite similar and both are slightly higher than a CBC Class $\mathrm{C}$ spectrum at periods of 0.75 to $2.0 \mathrm{sec}$ (Figure 25). The median and 84 th percentile deterministic spectra bound the other spectra (Figure 25). The 2009 rock spectrum is lower then the 2003 rock design spectrum at nearly all periods but higher than a Class B CBC spectrum (Figure 26). The median and 84th percentile rock deterministic spectra also bound the other spectra. 
The earthquake ground shaking hazard for the Central Campus has been estimated in terms of acceleration response spectra assuming an average site condition characterized by an alluvium thickness of $10.7 \mathrm{~m}(35 \mathrm{ft})$ over Franciscan rock. Rock spectra also have been calculated for sites on the eastern side of Campus. The "thin soil" site condition was assigned a $V_{\mathrm{S}} 30$ of 600 $\mathrm{m} / \mathrm{sec}$ based on assumed average $V_{S}$ values for the alluvium and rock of 370 and $715 \mathrm{~m} / \mathrm{sec}$, respectively. The site response of a thin soil site condition was not explicitly treated in the hazard analysis and thus ground motions in a future earthquake could exceed those estimated in this study. There also will be deviations from the average site condition assumed in this study for the Central Campus simply due to inherent geologic variability over a large area. Hence sitespecific geotechnical investigations to assess the $V_{S}$ of the alluvium and rock, the thickness of the alluvium, and any variability in these properties over the building footprint are recommended

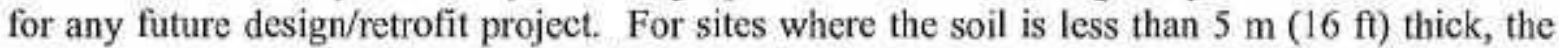
rock spectra can be used in structural design/evaluation. 
Abrahamson, N., 2000, Effects of rupture directivity on probabilistic seismic hazard analysis, Sixth International Conference on Seismic Zonation, v. I, p. 151-156.

Abrahamson, N.A. and Silva, W.J., 1997, Empirical response spectral attenuation relations for shallow crustal earthquakes: Seismological Research Letters, v. 68, p. 94-127.

Abrahamson, N.A. and Silva, W.J., 2008, Summary of the Abrahamson and Silva NGA ground motion relations. Earthquake Spectra, v. 24, p. 67-97.

Aki, K., 1983, Seismological evidence in support of the existence of "Characteristic Earthquakes": Earthquake Notes, v. 54, p. 60-61.

Anderson, J.G, 1979, Estimating the seismicity from geological structure for seismic risk studies: Bulletin of the Seismological Society of America, v, 69, p. 135-158.

Boore, D.M., and Atkinson, G.M., 2008, Ground motion predictive equations for the average horizontal component of PGA, PGV, and $5 \%$ damped PSA at spectral periods between $0.01 \mathrm{~s}$ to 10.0 s: Earthquake Spectra, v. 24, p. 99-138.

Bürgmann, R.D. Schmidt, R.M., Nadeau, M., d'Alessio, E., Fielding, D., Manaker, T.V., McEvilly, and Murray, M.H., 2000, Earthquake potential along the northern Hayward fault: Science v, 289, p, 1178-1182.

Campbell, K.W. and Bozorgnia, Y., 2008, NGA ground motion model for the geometric mean horizontal component of PGA, PGV, PGD, and 5\% damped linear elastic response spectra for periods ranging from 0.01 to $10 \mathrm{~s}$ : Earthquake Spectra, v. 24, p. 139-171.

Cao, T., Bryant, W.A, Rowshandel, B., Branum, D., Wills. C.J., 2003, The revised 2002 California probabilistic seismic hazard maps, June 2003: California Geological Survey, http://www.consrv.ca.gov/CGS/rghm/psha/fault_parameters/pdf/2002_CA_Hazard_Maps.pd f.

Chiou, B.S.J. and Youngs, R.R., 2008, An NGA model for the average horizontal component of peak ground motion and response spectra: Earthquake Spectra, v. 24, p. 173-215.

Cornell, C.A., 1968, Engineering seismic risk analysis: Bulletin of the Seismological Society of America, v. 58, p. 1583-1606.

dePolo, C.M., 1994, The maximum background earthquake for the Basin and Range Province, western North America: Bulletin of the Seismological Society of America, v. 84, p. 466-472.

Eurocode 8, 2003, Design procedures for earthquake resistance of structures - Part 5: foundations, retaining structures and geotechnical aspects. ENV 1998-5, CEN European Committee for Standardization, Brussels.

Galehouse, J.S., 1995, Theodolite measurements of creep rates on San Francisco Bay region faults, U.S. Geological Survey Open-file Report 95-210.

Geomatrix Consultants, 2000, Appendix One, Geologic hazards investigation central campus, University of California, Berkeley, California: unpublished report prepared for The Economic Benefits of a Disaster Resistant University. 
Hanks, T.C. and Kanamori, H. 1979, A moment magnitude scale: Journal of Geophysical Research, v. 84 , p. 2348-2350.

Idriss, I.M., 2008, An NGA empirical model for estimating the horizontal spectral values generated by shallow crustal earthquakes: Earthquake Spectra, v. 24, p. 217-242.

Keefer, D.I. and Bodily, S.E., 1983, Three-point approximations for continuous random variables: Management Science, v. 26, p. 595-609.

Lienkaemper, J.J., 1992, Map of recently active traces of the Hayward fault, Alameda and Contra Costa counties, California: U.S. Geological Survey Miscellaneous Field Studies Map MF2196, 1:24,000.

Lienkaemper, J.J. and Galehouse, J.S., 1997, Revised long-term creep rates on the Hayward fault, Alameda and Contra Costa Counties: California, U.S. Geological Survey Open-File Report 97-690, 18 p.

Lienkaemper, J.J. Schwartz, D.P., Kelson, K.I., Lettis, W.R., Simpson, G.D., Southon, J.R. Wanket, J.A., Williams, P.L., 1999, Timing of paleoearthquakes on the northern Hayward fault - preliminary evidence in El Cerrito, California: U.S. Geological Survey Open-File Report 99-318, p. 34.

Lienkaemper, J.J. and Williams, P.L., 2007, A 1650-year record of large earthquake on the southern Hayward fault: Bulletin of the Seismological Society of America, in press.

Molnar, P., 1979, Earthquake recurrence intervals and plate tectonics: Bulletin of the Seismological Society of America, v. 69, p. 115-133.

Oppenheimer, D.H. and Macgregor-Scott, N., 1992, The seismotectonics of the eastern San Francisco Bay region, in Proceedings of the Second Conference on Earthquake Hazards in the Eastern San Francisco Bay Area, Borchardt, G., Hirschfeld, S.E., Lienkaemper, J.J., McClellan, P., Williams, P.L. and Wong, I.G. (eds.), California Division of Mines and Geology Special Publication 113, p. 11-16.

Pagliaroli, A., Lanzo, G., and D'Elia, B., 2006, Numerical study of the topography effects at the Nicastro (Southern Italy) cliff and comparison with EC8 recommendations. Proceedings of the ETC Workshop on Evaluation and Application of Eurocode 8, 2003-2006, p. 209-218. National Technical University, Athens, Greece.

Schwartz, D.P. and Coppersmith, K.J., 1984, Fault behavior and characteristic earthquakes-examples from the Wasatch and San Andreas fault zones: Journal of Geophysical Research, v. 89 , p. $5681-5698$.

Schwartz, D.P., Pantosti, D., Hecker, S., Okomura, K., Budding, K.E. and Powers, T., 1992, Late Holocene behavior and seismogenic potential of the Rodgers Creek fault zone, Sonoma County, California, in Proceedings of the Second Conference on Earthquake Hazards in the Eastern San Francisco Bay Area, Borchardt, G., Hirschfeld, S.E., Lienkaemper, J.J., McClellan, P., Williams, P.L. and Wong, I.G. (eds.), California Division of Mines and Geology Special Publication 113, p. 393-398. 
Simpson, R.W., Lienkaemper, J.J., and Galehouse, J.S., 2001, Variations in creep rate along the Hayward fault, California, interpreted as changes in depth of creep, Geophysical Research Letters, v. 28 , p. $2,269-2,272$.

Somerville, P.G., Smith, N.F., Graves, R.W., and Abrahamson, N.A., 1997, Modification of empirical strong ground motion attenuation relations to include the amplitude and duration effects of rupture directivity, Seismological Research Letters, v. 68, p. 199-222.

Toppozada, T.R. and Borchardt, G., 1998, Re-evaluation of the 1836 "Hayward fault" and 1838 San Andreas fault earthquakes: Bulletin of the Seismological Society of America, v. 88, p. 140-159.

URS Corporation, 2003, UC Berkeley Seismic Guidelines, Appendix I: Probabilistic groundmotion analysis for Central Campus and Appendix II: Commentary on earthquake hazard levels: Seismic and Structural Engineering Guidelines, University of California, Berkeley Capital Projects.

URS Corporation, 2001, Deterministic and probabilistic seismic hazard analyses, Folsom Dam, central California, unpublished report prepared for U.S. Army Corps of Engineers.

Wagner, D.L. and Bortugno, E.J., 1982, Geologic map of the Santa Rosa quadrangle: California Division of Mines and Geology, Regional Geologic Map Series No. 2A, 1:250,000.

Wells, D.L. and Coppersmith, K.J., 1994, New empirical relationships among magnitude, rupture length, rupture width, rupture area, and surface displacement: Bulletin of the Seismological Society of America, v. 84, p. 974-1002.

Wesnousky, S.G., 1986, Earthquakes, Quaternary faults, and seismic hazard in California: Journal Geophysical Research, v. 91, p. 12,587-12,631.

Wills, C.J. and Clahan, K.B., 2006, Developing a map of geologically defined site-condition categories for California: Bulletin of the Seismological Society of America, v. 96, p. 14831501 .

Wong, L.G., 1991, Contemporary seismicity, active faulting and seismic hazards of the Coast Ranges between San Francisco Bay and Healdsburg, California: Journal of Geophysical Research, v. 96, p. 19891-19904.

Wong, I.G., Thomas, P.A., and Abrahamson, N., 2004, The PEER-Lifelines validation of software used in probabilistic seismic hazard analysis, in 2004 Geotechnical Engineering for Transportation Projects, Proceedings, M. Yegian and E. Kavazanjian (eds.), American Society of Civil Engineers, Geotechnical Special Publication No. 126, v, 1, p. 807-815.

Wong, I., Thomas, P., Unruh, J., Hanson, K., and Youngs, R., 2008, Characterizing the earthquake ground shaking hazard in the Sacramento-San Joaquin Delta, California: Geotechnical Earthquake Engineering and Soil Dynamics IV Conference Proceedings (CD ROM).

Working Group for California Earthquake Probabilities (WGCEP), 2003, Earthquake probabilities in the San Francisco Bay area: 2002-2031: U.S. Geological Survey Open-File Report 03-214. 
Working Group on Northern California Earthquake Potential (WGNCEP), 1996, Database of potential sources for earthquakes larger than magnitude 6 in northern California: U.S. Geological Survey Open-File Report 96-705, 53 p.

Youngs, R.R. and Coppersmith, K.J., 1985, Implications of fault slip rates and earthquake recurrence models to probabilistic seismic hazard estimates: Bulletin of the Seismological Society of America, v. 75 , p. 939-964.

Youngs, R.R, Coppersmith, K.J., Taylor, C.L., Power, M.S., Di Silvestro, L.A., Angell, M.L., Hall, N.T., Wesling, J.R., and Mualchin, L., 1992, A comprehensive seismic hazard model for the San Francisco Bay Region, in Proceedings of the Second Conference on Earthquake Hazards in the Eastern San Francisco Bay Area, Borchardt, G., Hirschfeld, S.E., Lienkaemper, J.J., McClellan, P., Williams, P.L. and Wong, I.G. (eds.), California Division of Mines and Geology Special Publication 113, p. 431-441. 
Table 1

Design Response Spectral Accelerations for UCB Thin Soil and Rock in g's

\begin{tabular}{|c|c|c|c|c|c|c|c|c|}
\hline \multirow{3}{*}{ Period (sec) } & \multicolumn{8}{|c|}{ Return Period } \\
\hline & \multicolumn{2}{|c|}{72 yrs } & \multicolumn{2}{|c|}{$475 \mathrm{yrs}$} & \multicolumn{2}{|c|}{949 yrs } & \multicolumn{2}{|c|}{2,475 yrs } \\
\hline & $\begin{array}{l}\text { Thin } \\
\text { Soil }\end{array}$ & Rock & $\begin{array}{l}\text { Thin } \\
\text { Soil }\end{array}$ & Rock & $\begin{array}{l}\text { Thin } \\
\text { Soil }\end{array}$ & Rock & $\begin{array}{l}\text { Thin } \\
\text { Soil }\end{array}$ & Rock \\
\hline 0.01 & 0.36 & 0.33 & 0.85 & 0.84 & 1.03 & 1.02 & 1.37 & 1.37 \\
\hline 0.03 & 0.38 & 0.36 & 0.93 & 0.92 & 1.12 & 1.12 & 1.52 & 1.52 \\
\hline 0.1 & 0.67 & 0.65 & 1.64 & 1.68 & 2.00 & 2.06 & 2.72 & 2.82 \\
\hline 0.15 & 0.78 & 0.76 & 1.91 & 1.95 & 2.33 & 2.39 & 3.18 & 3.28 \\
\hline 0.2 & 0.81 & 0.76 & 2.00 & 1.99 & 2.47 & 2.46 & 3.37 & 3.39 \\
\hline 0.3 & 0.74 & 0.64 & 1.86 & 1.67 & 2.28 & 2.08 & 3.14 & 2.91 \\
\hline 0.5 & 0.56 & 0.45 & 1.46 & 1.20 & 1.81 & 1.49 & 2.51 & 2.10 \\
\hline 0.75 & 0.40 & 0.31 & 1.05 & 0.83 & 1.31 & 1.04 & 1.83 & 1.47 \\
\hline 1.0 & 0.31 & 0.24 & 0.81 & 0.64 & 1.01 & 0.80 & 1.42 & 1.13 \\
\hline 2.0 & 0.14 & 0.11 & 0.38 & 0.29 & 0.48 & 0.37 & 0.68 & 0.53 \\
\hline 3.0 & 0.08 & 0.06 & 0.23 & 0.18 & 0.29 & 0.22 & 0.42 & 0.32 \\
\hline 4.0 & 0.06 & 0.04 & 0.16 & 0.12 & 0.21 & 0.15 & 0.30 & 0.23 \\
\hline 5.0 & 0.04 & 0.03 & 0.12 & 0.10 & 0.16 & 0.12 & 0.24 & 0.18 \\
\hline
\end{tabular}


Table 2

Design Response Spectral Accelerations for LBNL in g's

\begin{tabular}{|c|c|c|c|c|}
\hline \multirow{2}{*}{ Period (sec) } & \multicolumn{4}{|c|}{ Return Period } \\
\cline { 2 - 5 } & $\mathbf{7 2}$ yrs & $\mathbf{4 7 5}$ yrs & $\mathbf{9 4 9}$ yrs & 2,475 yrs \\
\hline 0.01 & 0.36 & 0.86 & 1.04 & 1.39 \\
\hline 0.03 & 0.39 & 0.95 & 1.14 & 1.53 \\
\hline 0.1 & 0.67 & 1.66 & 2.03 & 2.77 \\
\hline 0.15 & 0.79 & 1.94 & 2.37 & 3.22 \\
\hline 0.2 & 0.82 & 2.02 & 2.50 & 3.42 \\
\hline 0.3 & 0.76 & 1.87 & 2.30 & 3.18 \\
\hline 0.5 & 0.58 & 1.51 & 1.87 & 2.59 \\
\hline 0.75 & 0.41 & 1.10 & 1.36 & 1.91 \\
\hline 1.0 & 0.32 & 0.85 & 1.06 & 1.49 \\
\hline 2.0 & 0.14 & 0.40 & 0.50 & 0.72 \\
\hline 3.0 & 0.09 & 0.25 & 0.31 & 0.45 \\
\hline 4.0 & 0.06 & 0.17 & 0.22 & 0.32 \\
\hline 5.0 & 0.04 & 0.13 & 0.17 & 0.26 \\
\hline
\end{tabular}




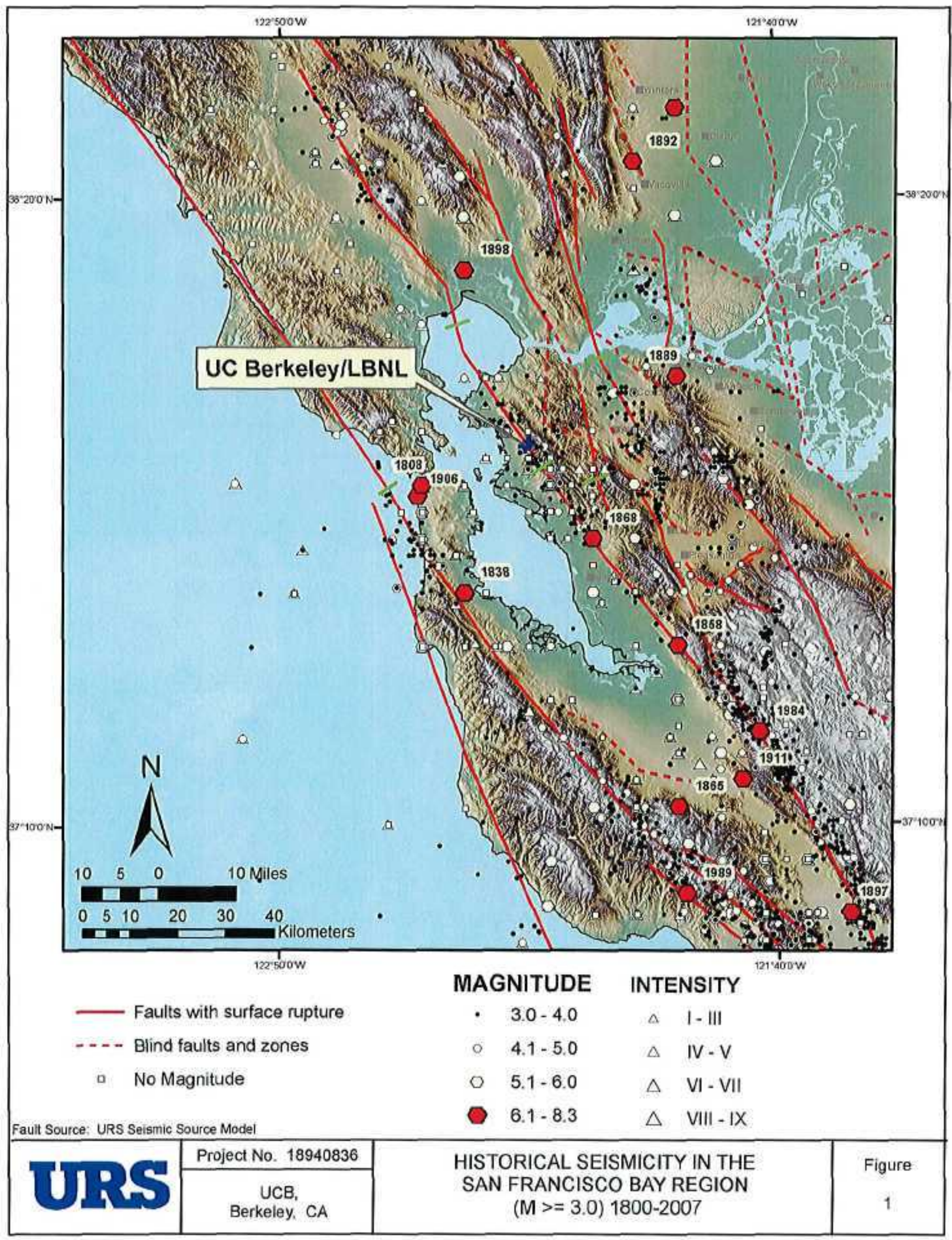




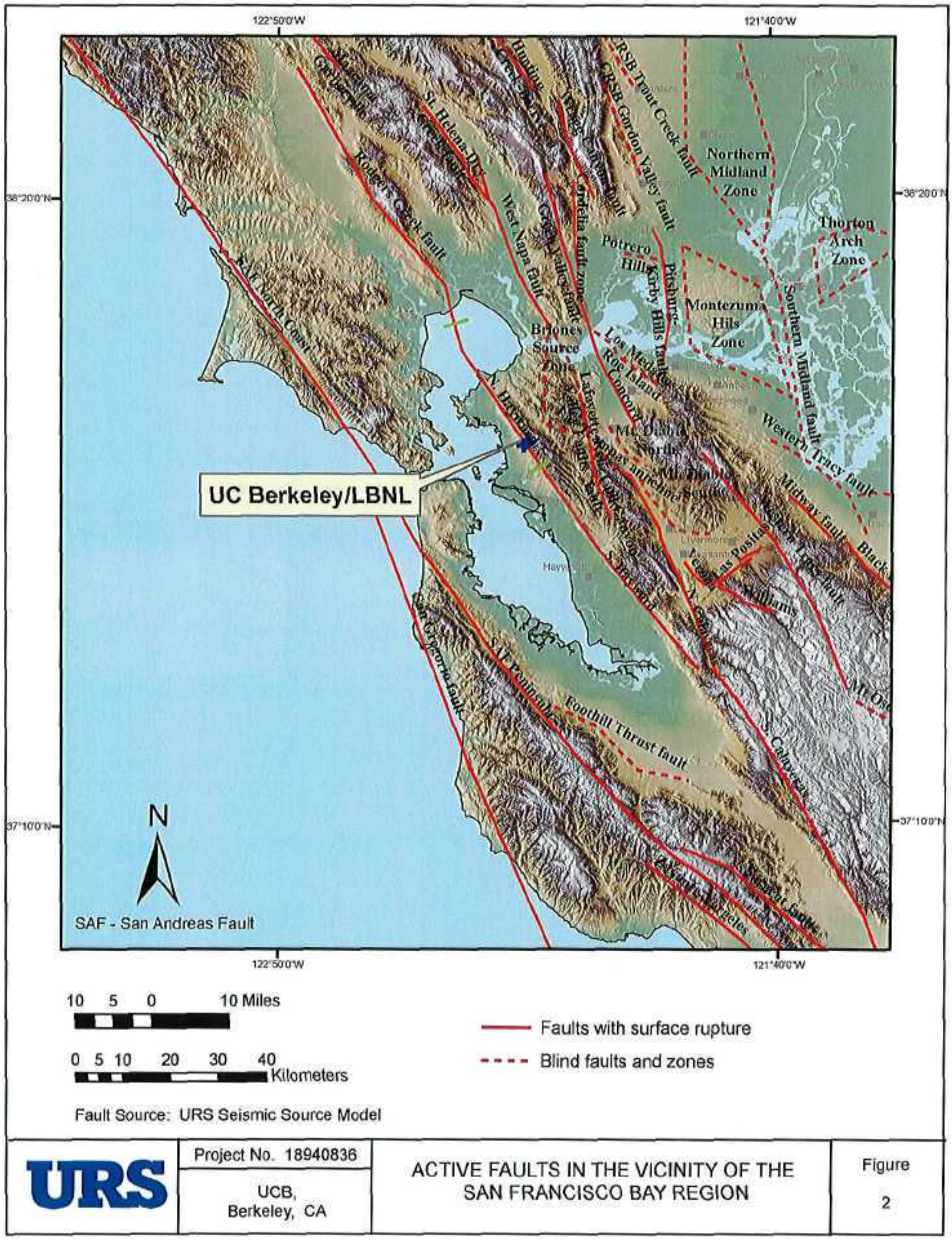




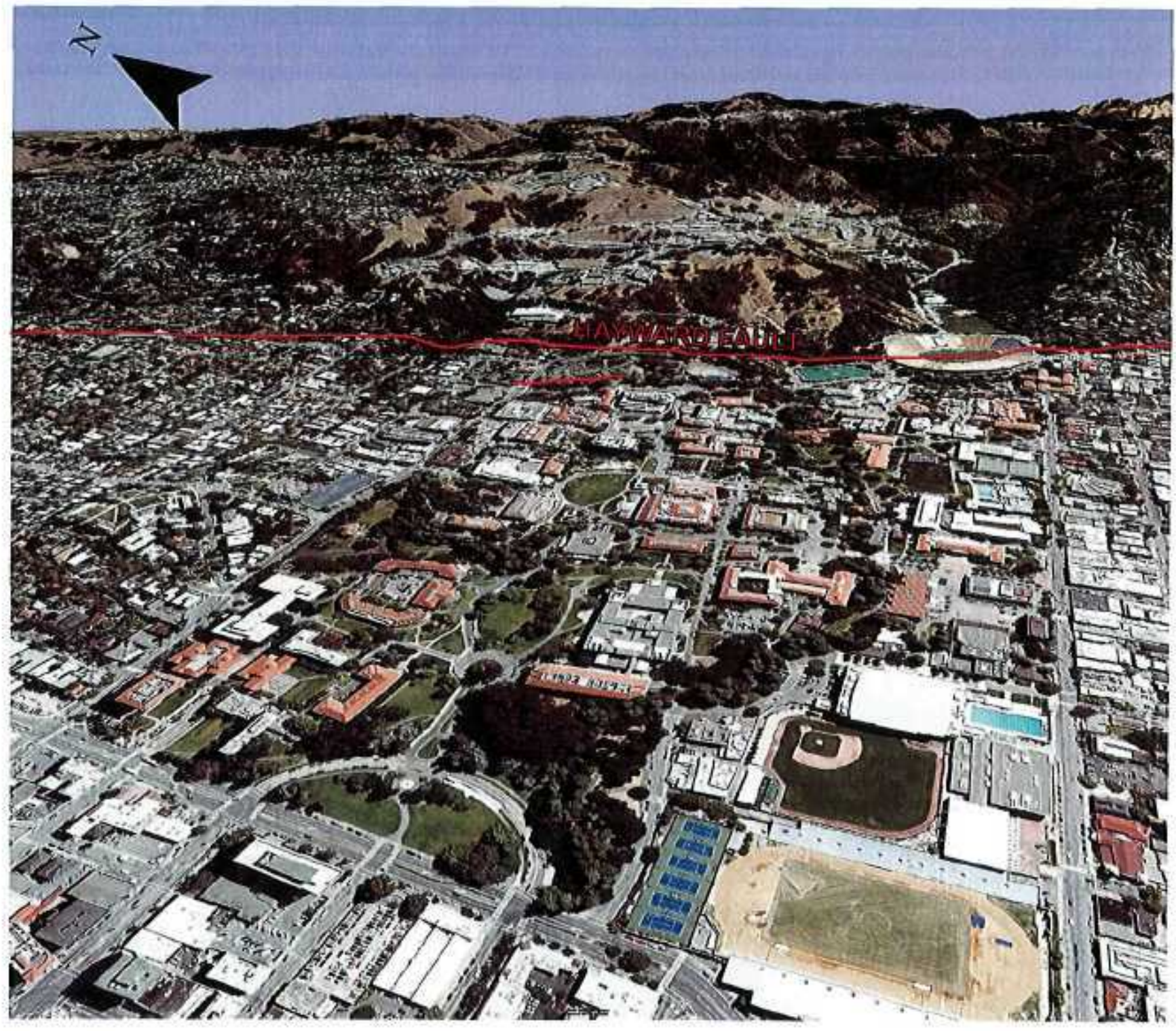

\begin{tabular}{|c|c|c|c|}
\hline & Project No. 18940836 & $\begin{array}{c}\text { GOOGLE EARTH IMAGE OF THE } \\
\text { UCB AND LBNLAND THE HAYWARD FAULT }\end{array}$ & Figure \\
\cline { 2 - 2 } & $\begin{array}{c}\text { UCB, } \\
\text { Berkeley, CA }\end{array}$ & 3 & 3 \\
\hline
\end{tabular}




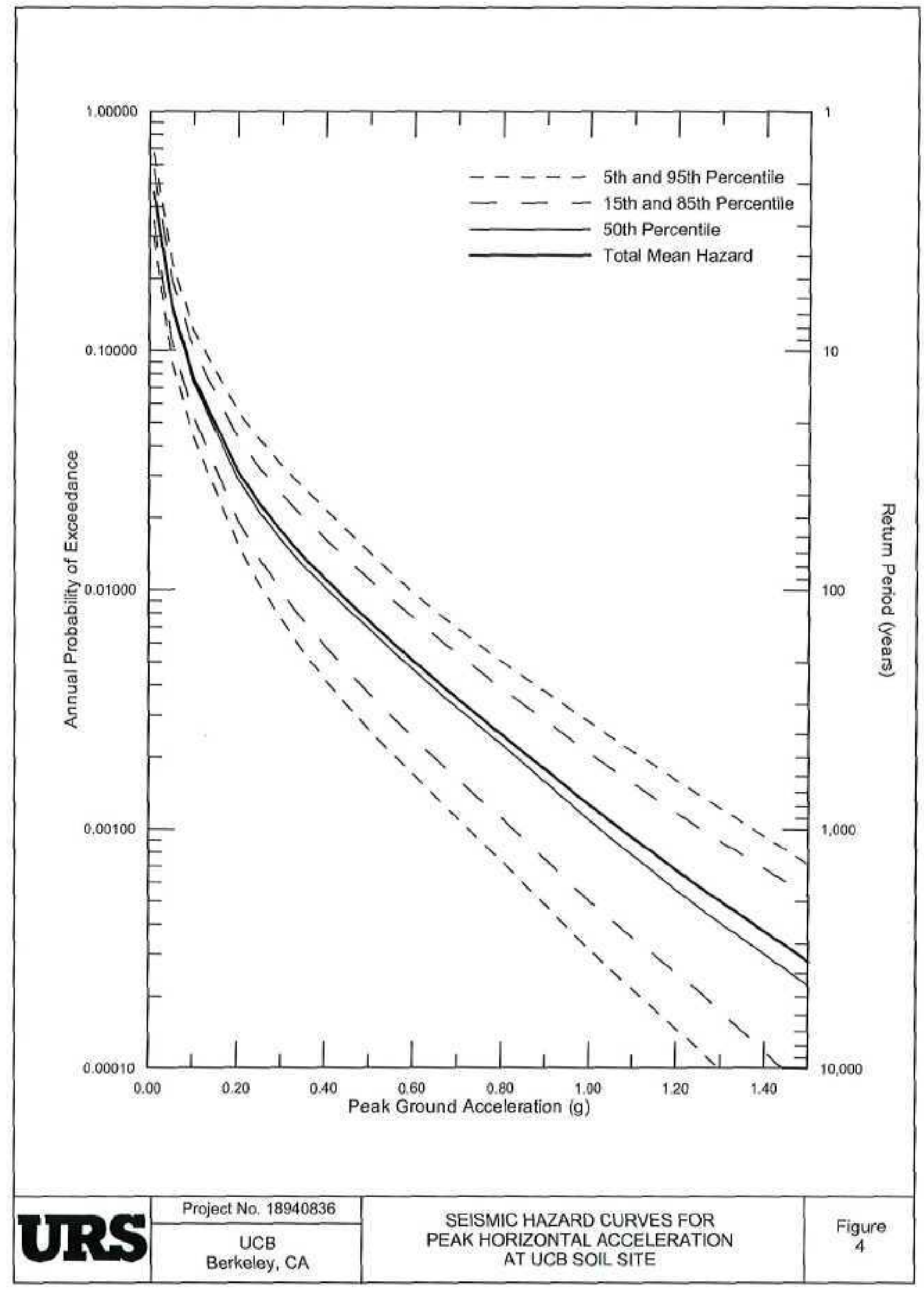




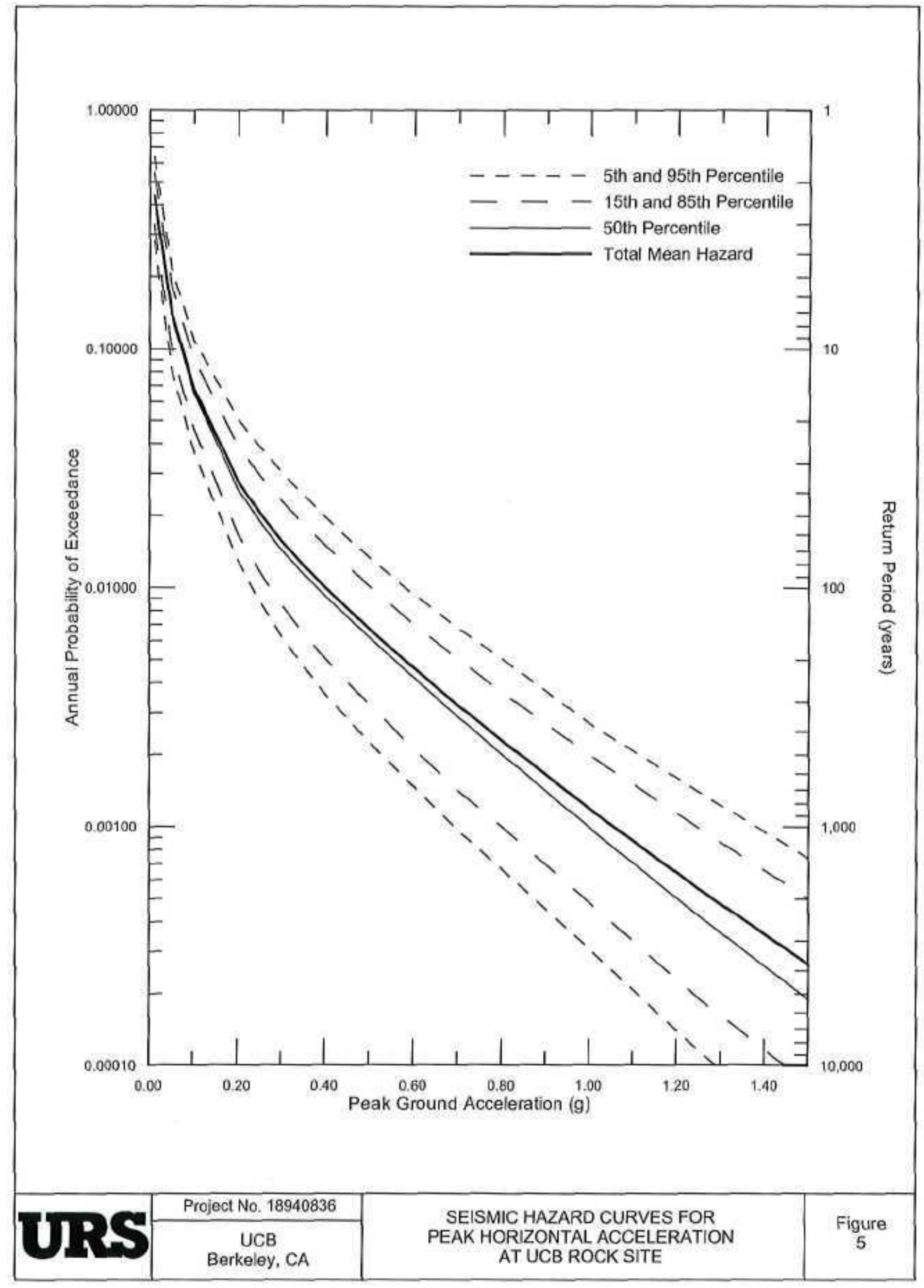




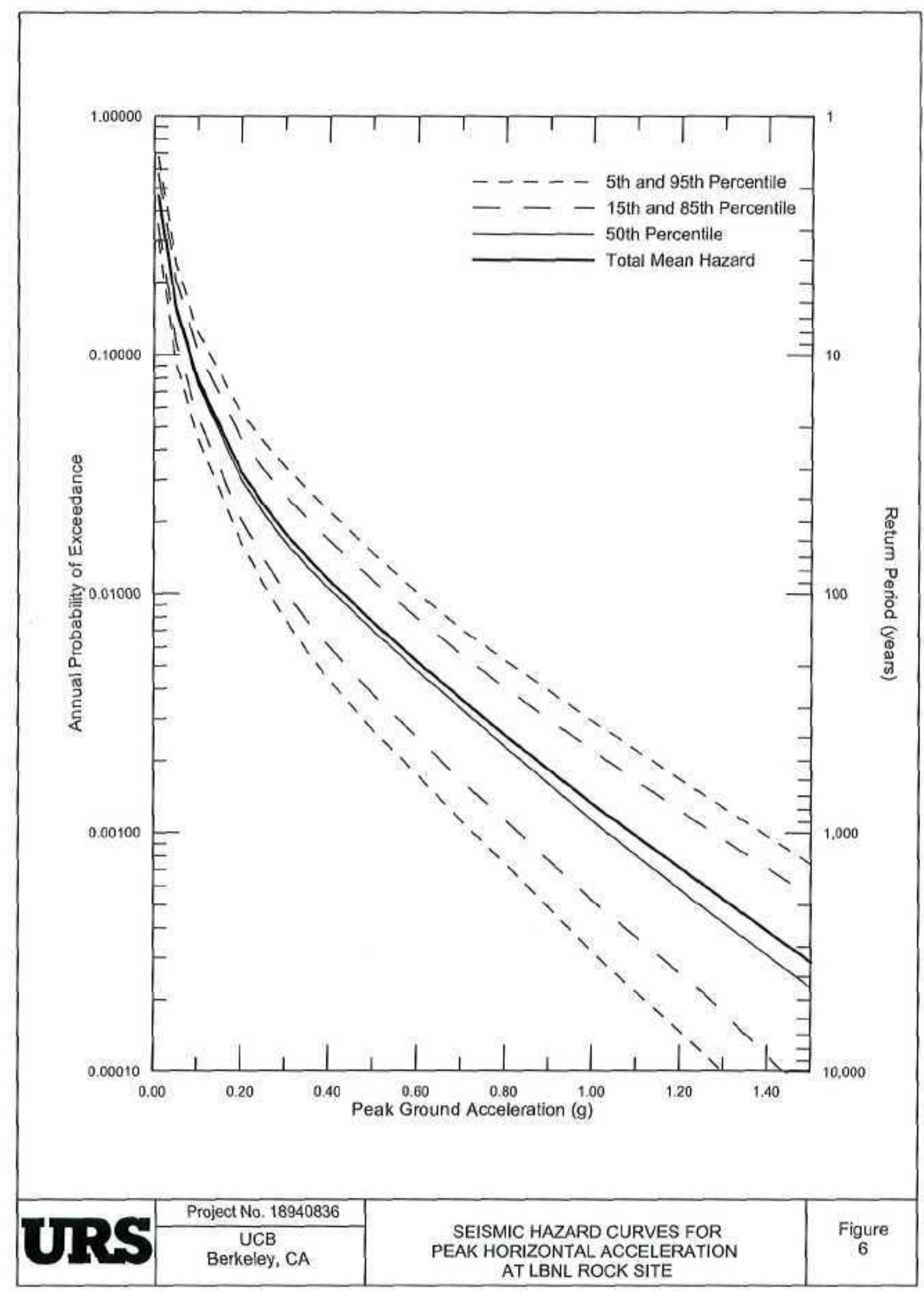




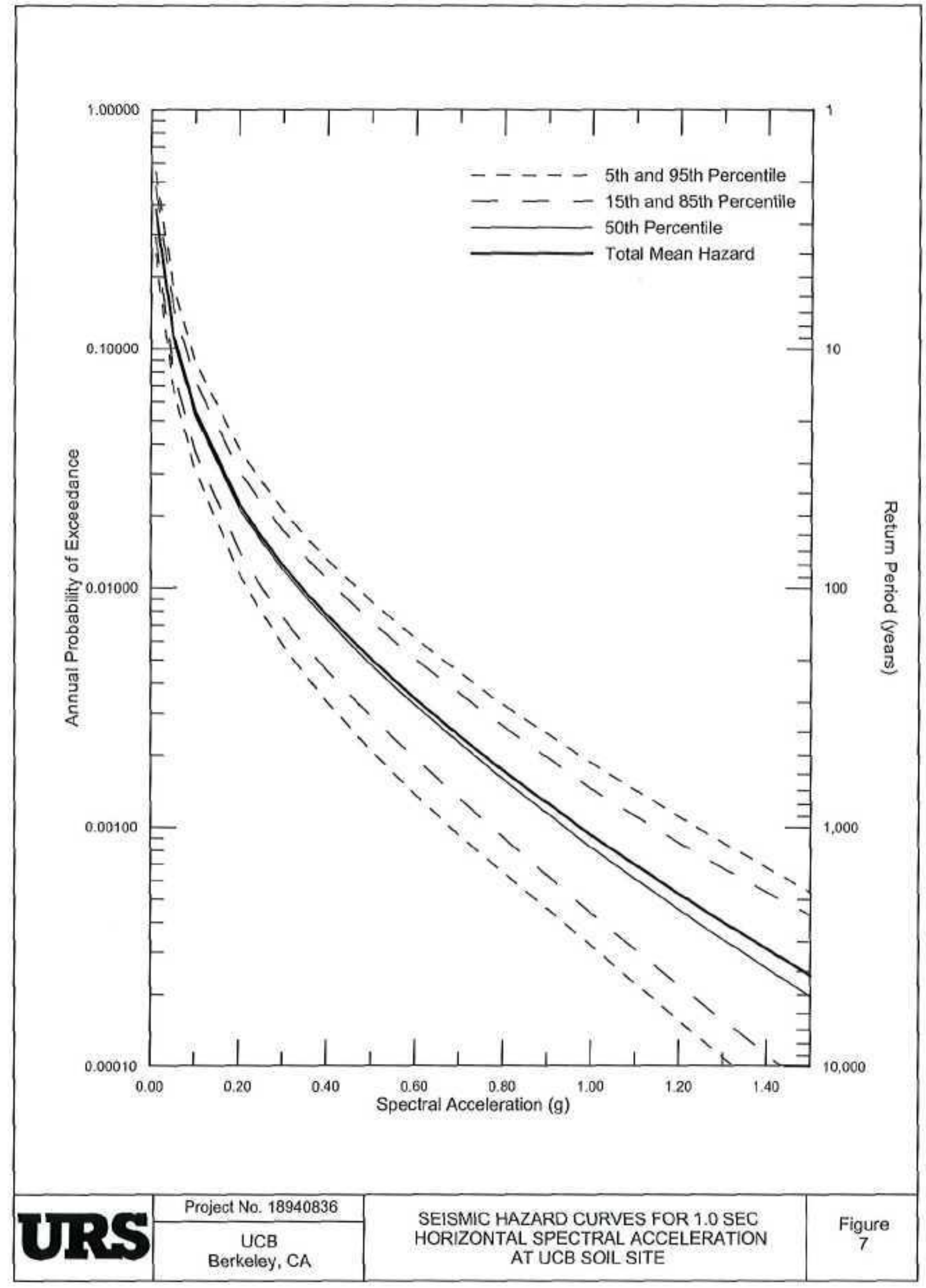




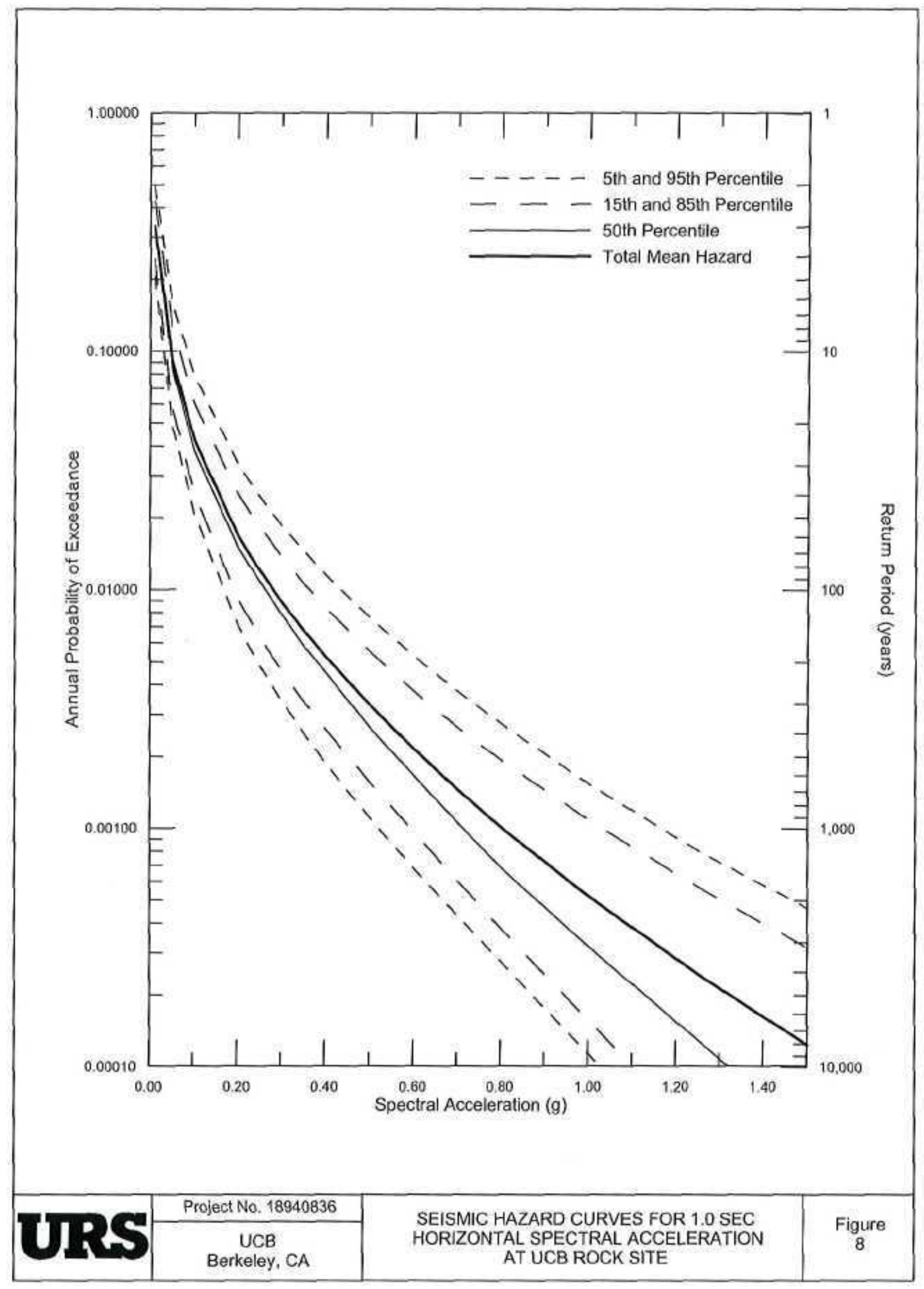




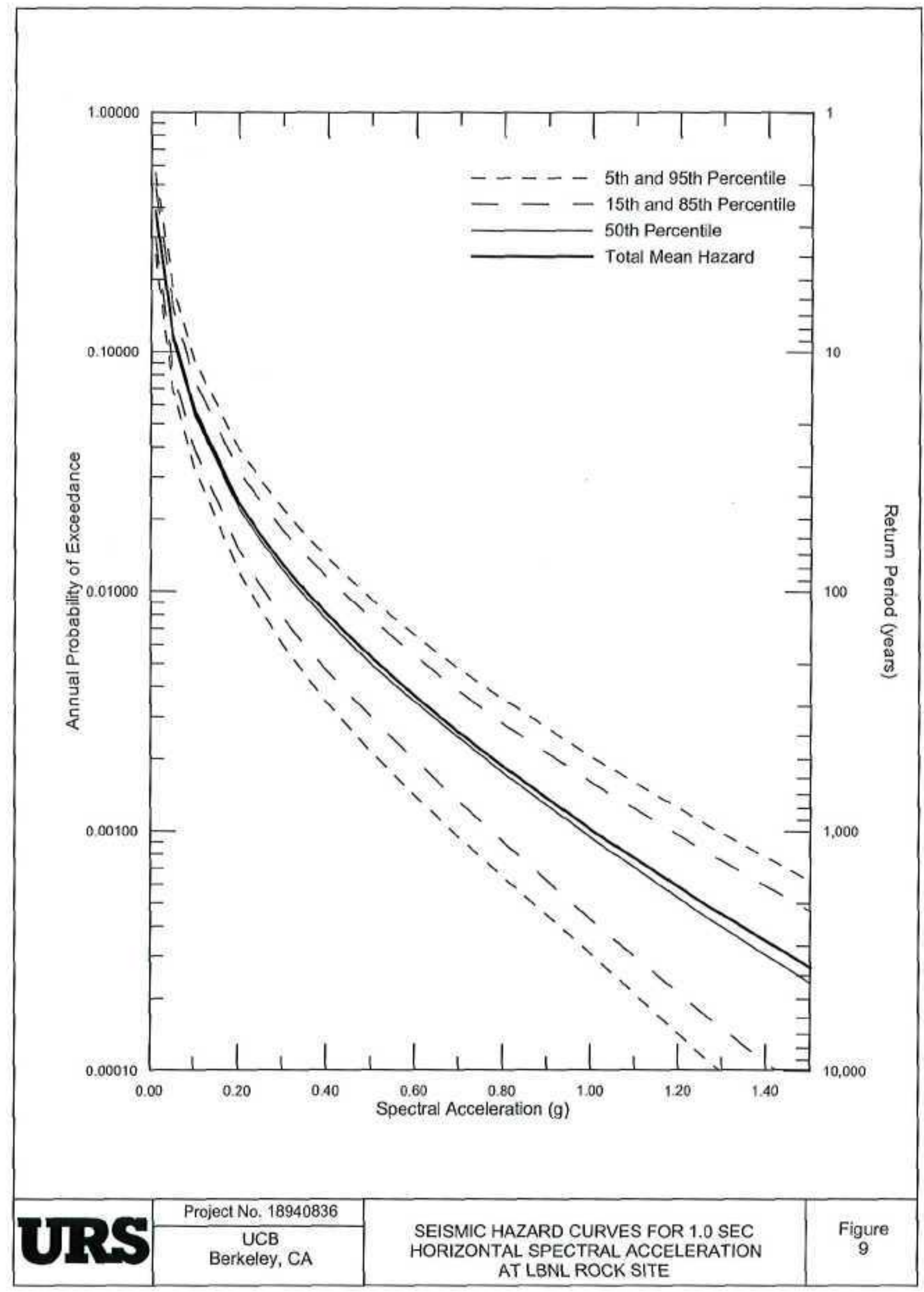




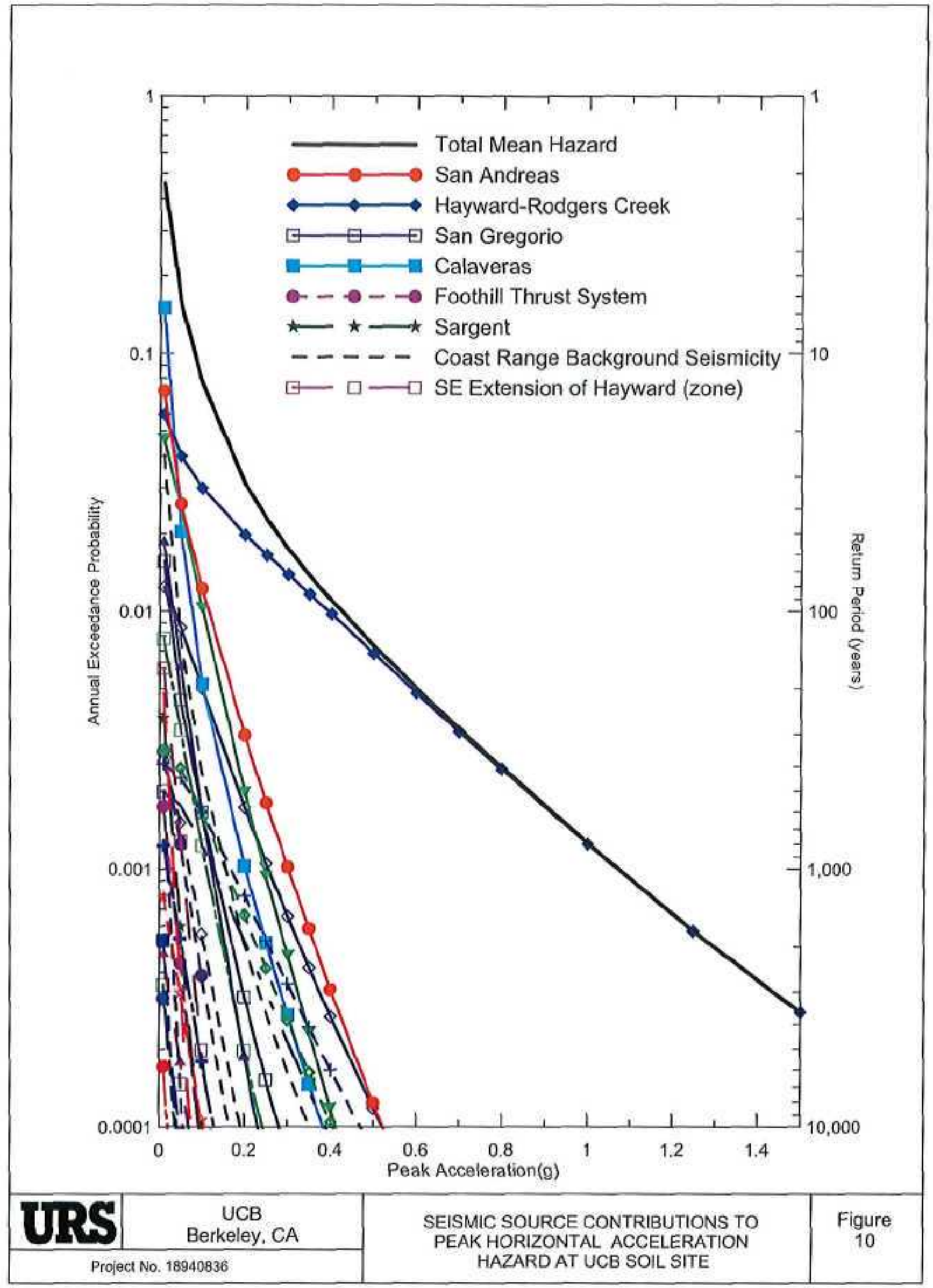




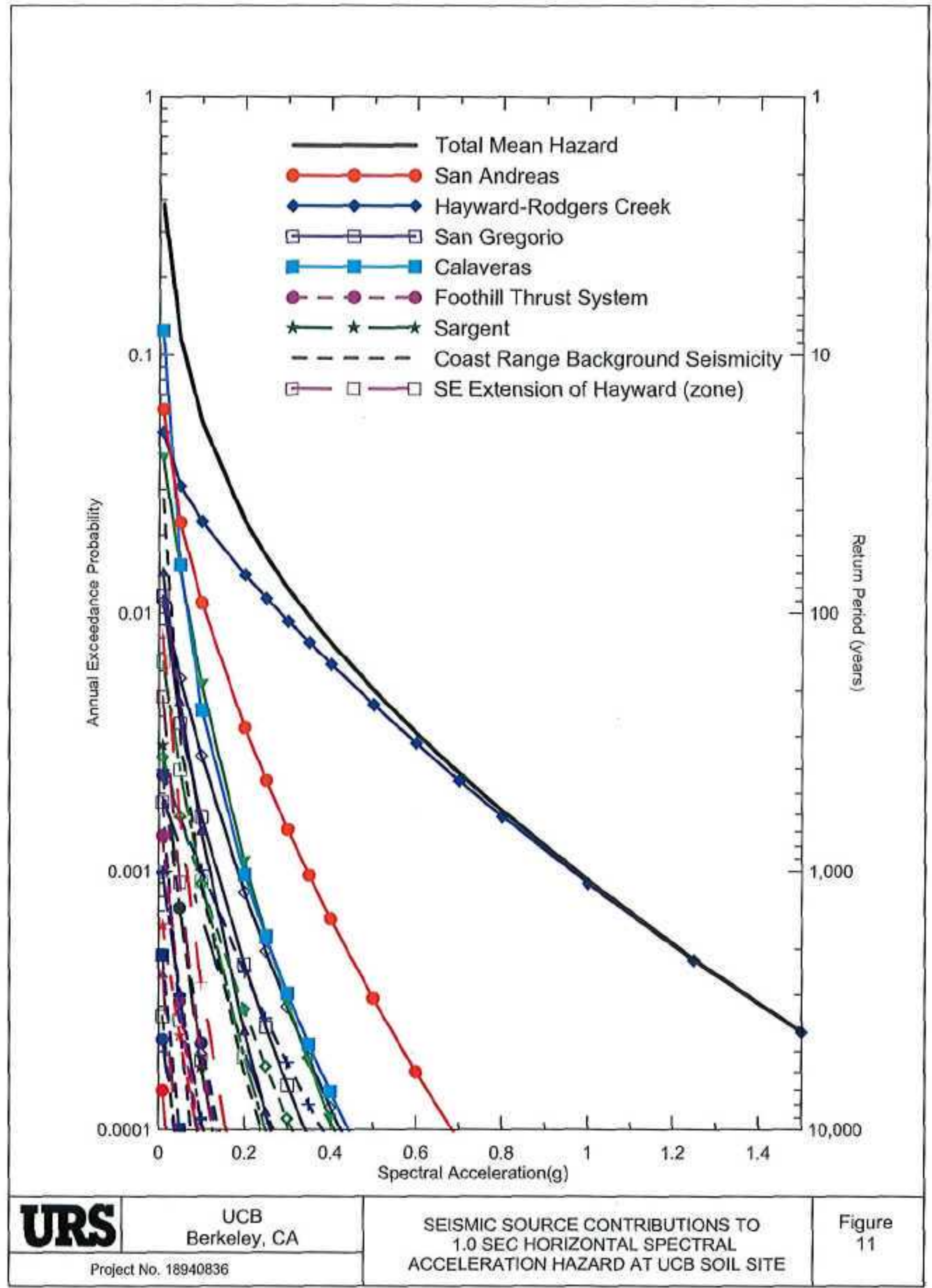




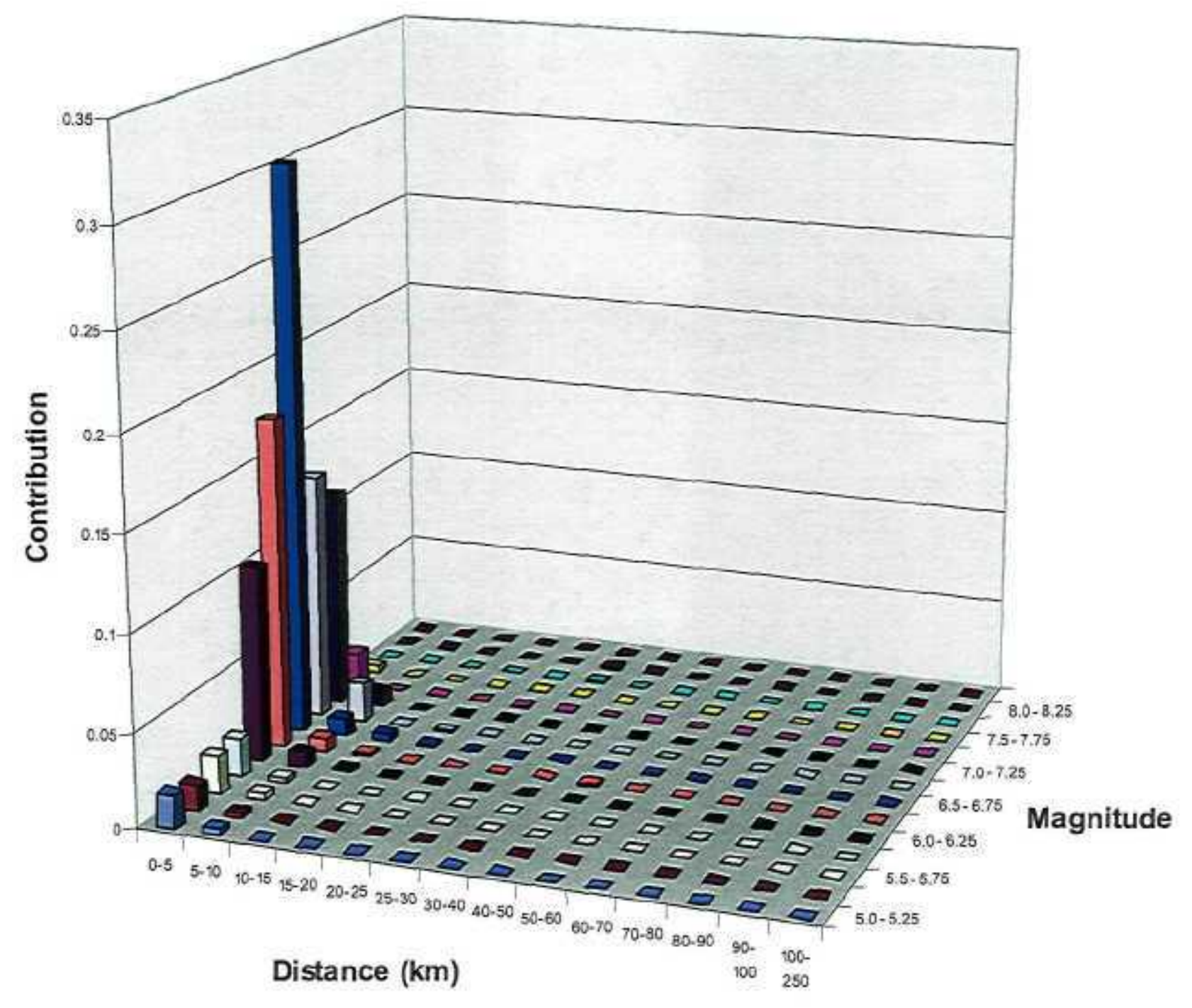

\begin{tabular}{l|l|l} 
& Project No. 18940836 \\
& MAGNITUDE AND DISTANCE CONTRIBUTIONS
\end{tabular} $\begin{array}{ll}\text { U1 } & \text { UCB } \\ \text { Berekeley, CA } & \text { TO THE MEAN PEAK HORIZONTAL } \\ \text { ACCELERATION HAZARD AT 475-YEAR } \\ \text { RETURN PERIOD AT UCB SOIL SITE }\end{array}$ 


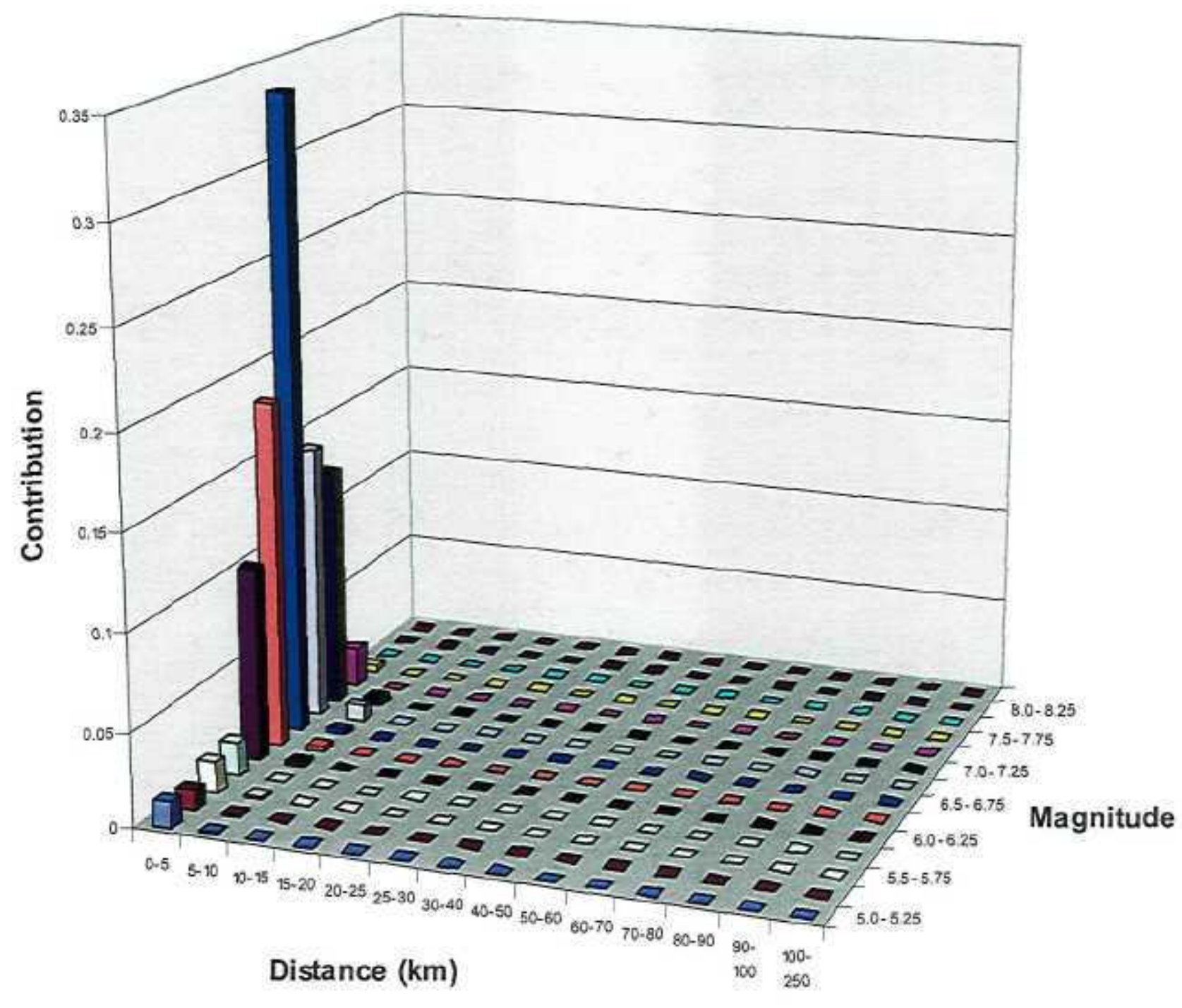

\begin{tabular}{|c|c|c|c|}
\hline \multirow{2}{*}{10} & Project No. 18940836 & \multirow{2}{*}{$\begin{array}{l}\text { MAGNITUDE AND DISTANCE CONTRIBUTIONS } \\
\text { TO THE MEAN PEAK HORIZONTAL } \\
\text { ACCELERATION HAZARD AT 2,475-YEAR } \\
\text { RETURN PERIOD AT UCB SOIL SITE }\end{array}$} & \multirow[b]{2}{*}{$\begin{array}{c}\text { Figure } \\
13\end{array}$} \\
\hline & $\begin{array}{c}\text { UCB } \\
\text { Berekeley, CA }\end{array}$ & & \\
\hline
\end{tabular}




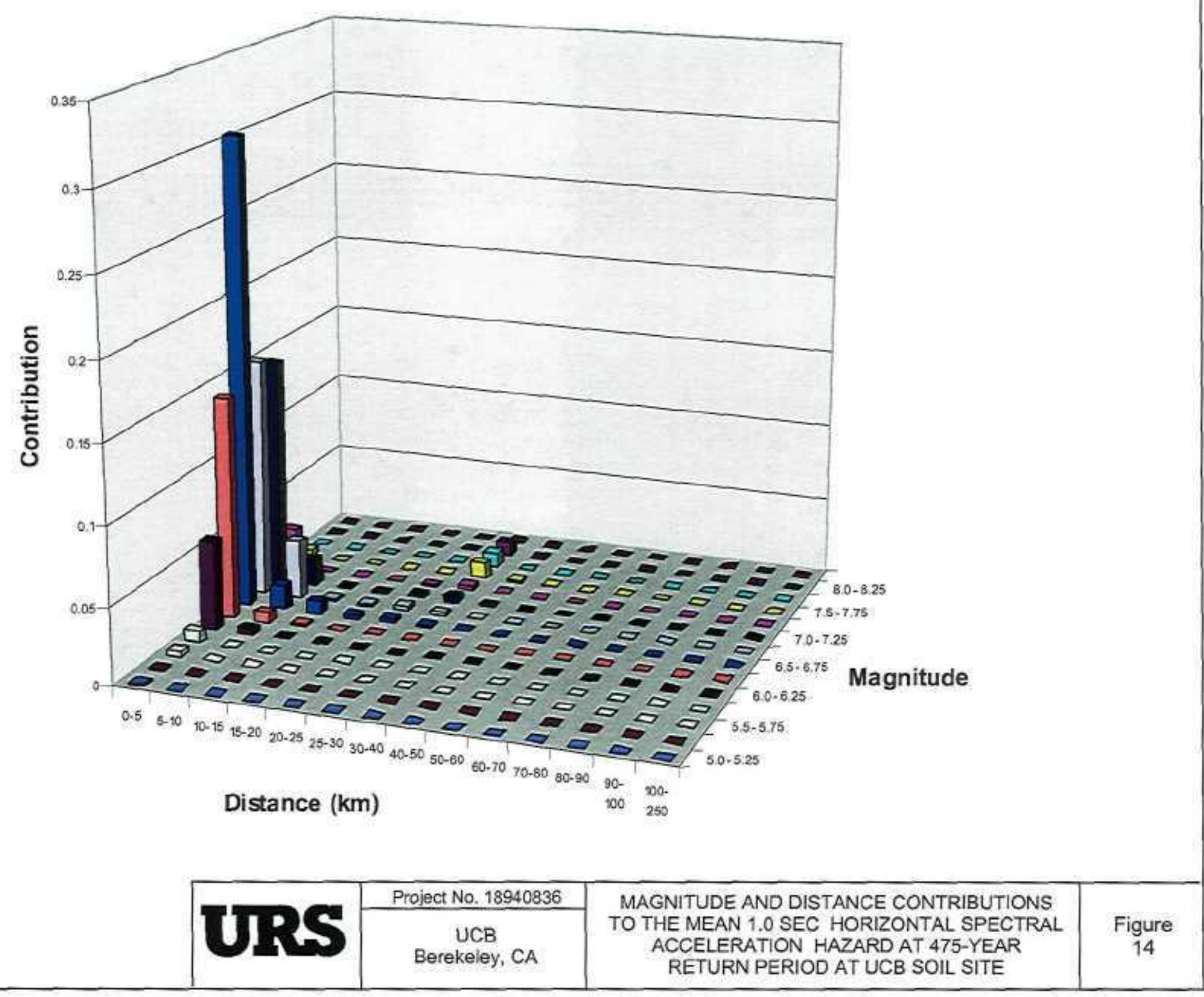




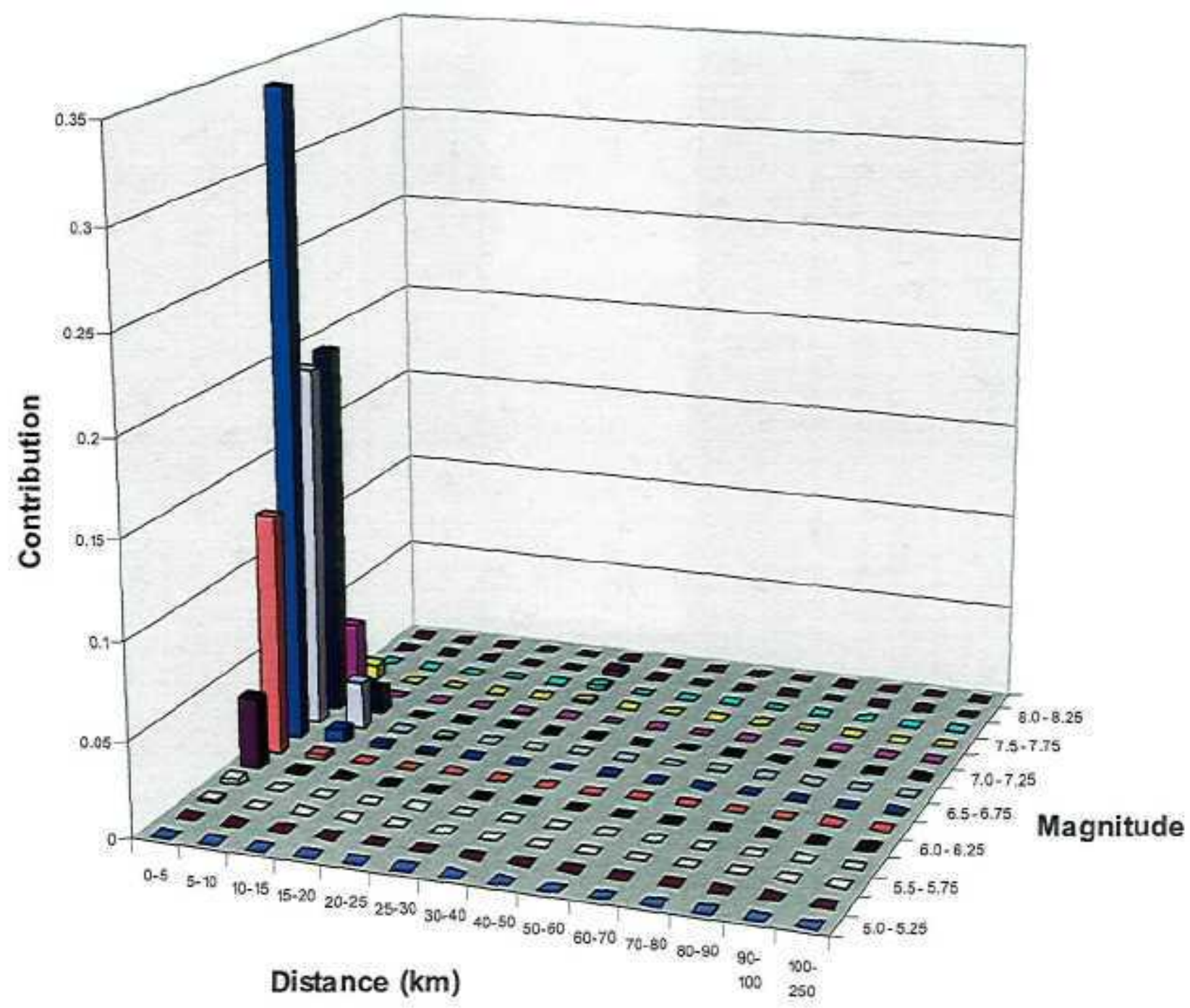

\begin{tabular}{l|c|c} 
M. & MAGNITUDE AND DISTANCE CONTRIBUTIONS \\
& TO THE MEAN 1.0 SEC HORIZONTAL SPECTRAL
\end{tabular} Berekeley, CA ACCELERATION HAZARD AT 2,475-YEAR RETURN PERIOD AT UCB SOIL SITE 


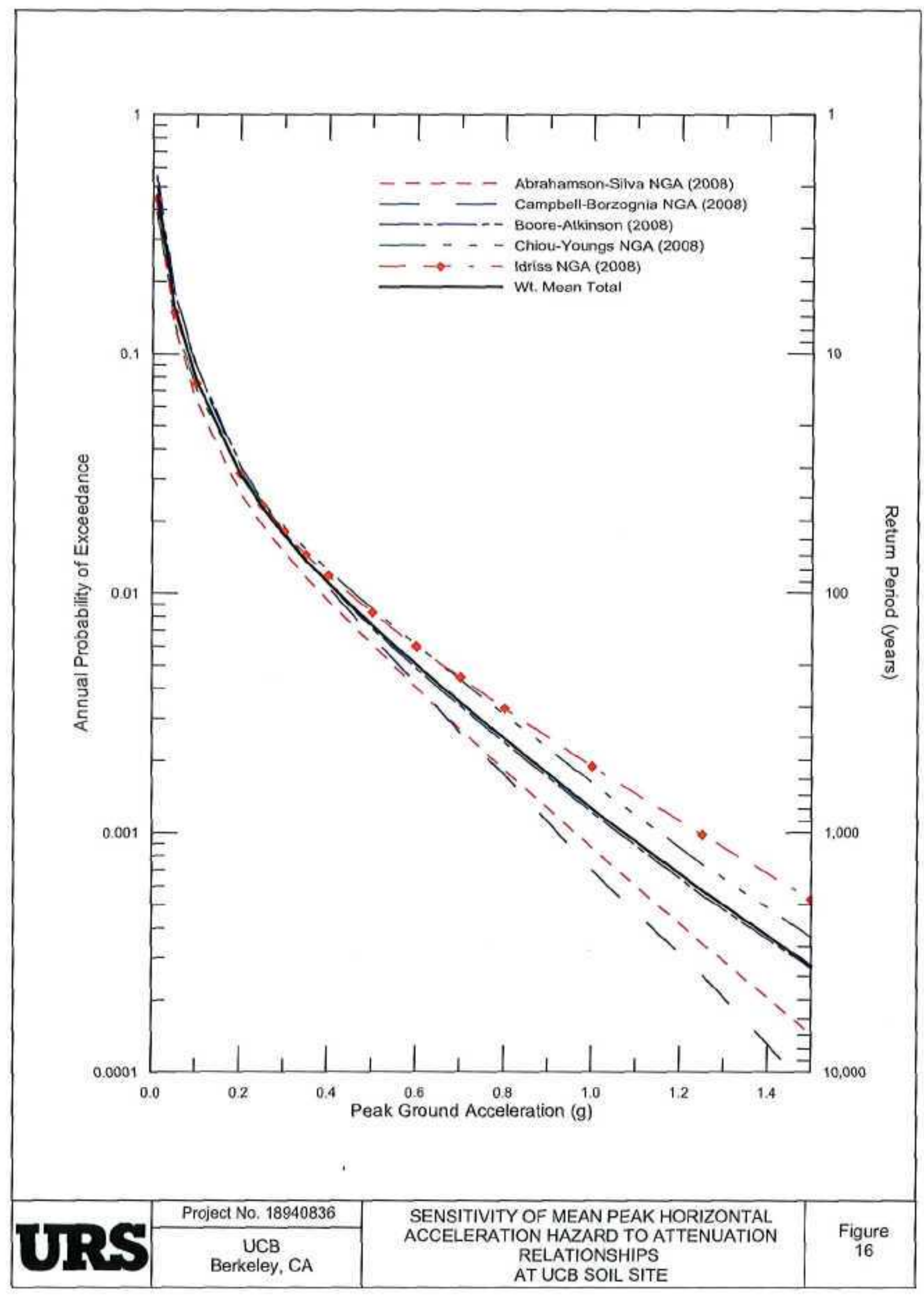




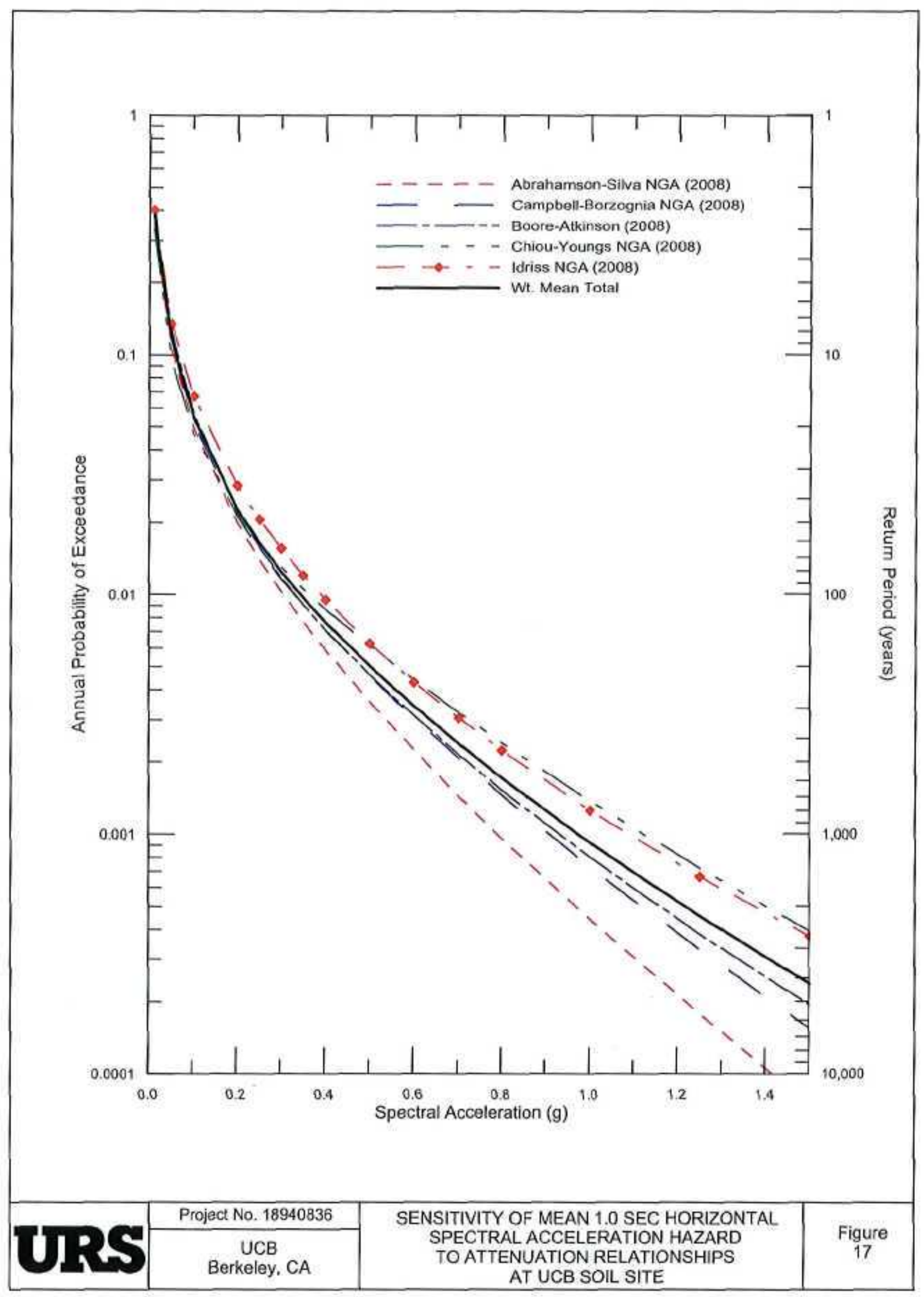




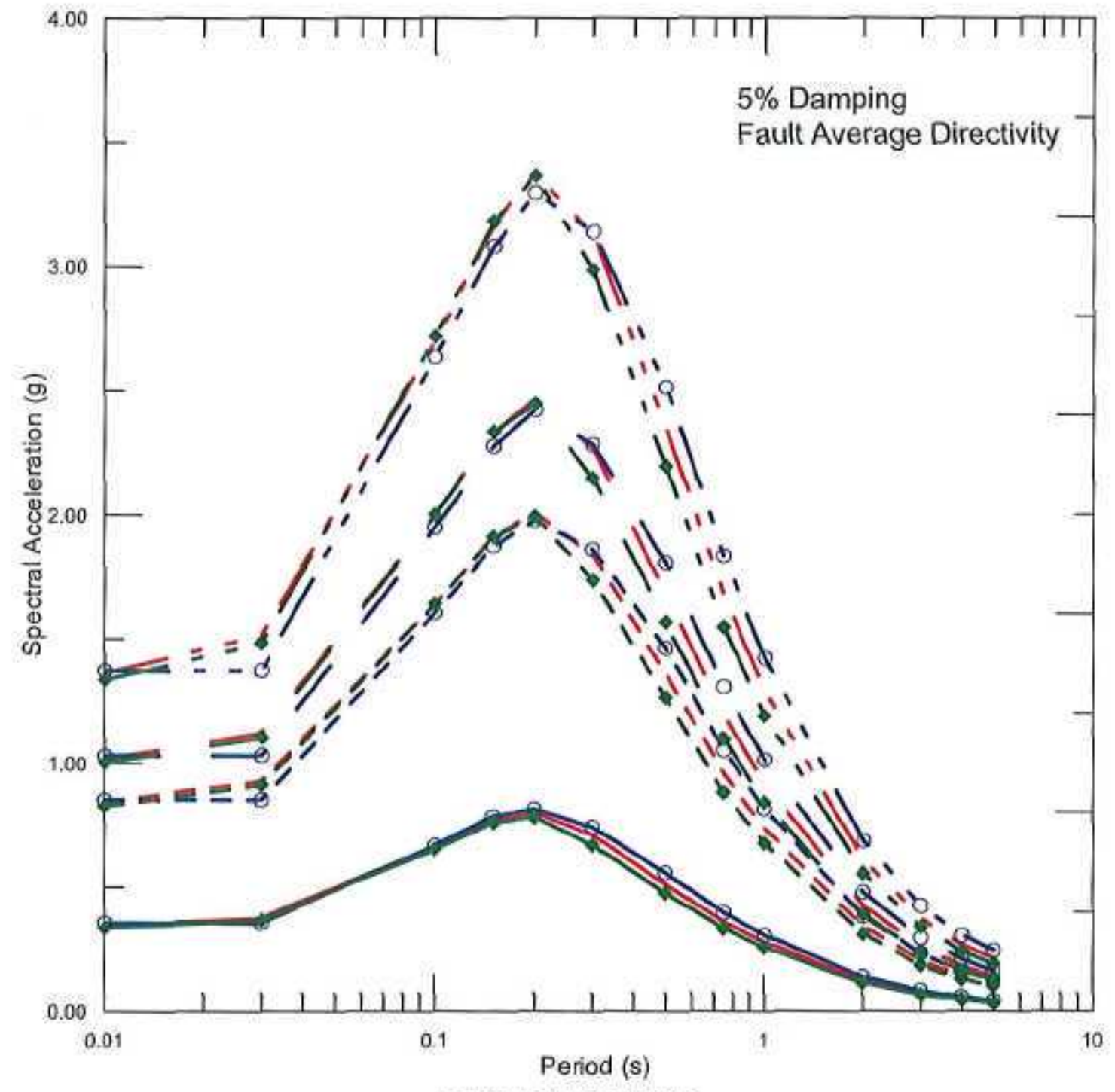

RETURN PERIOD

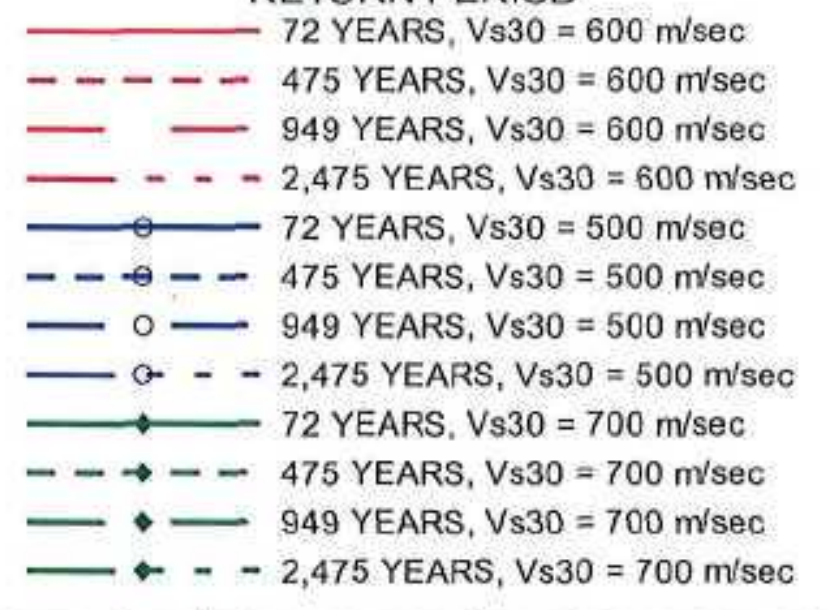



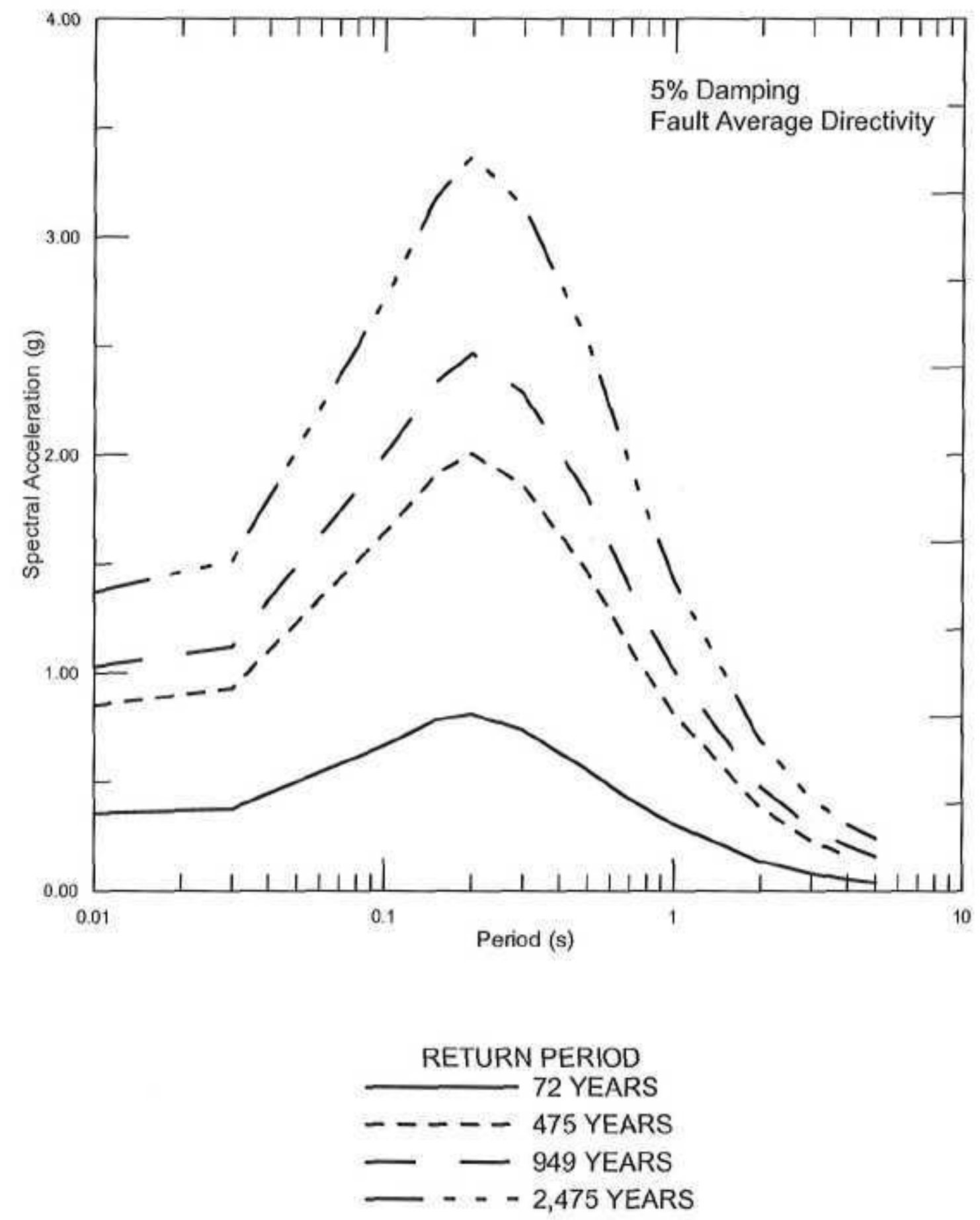


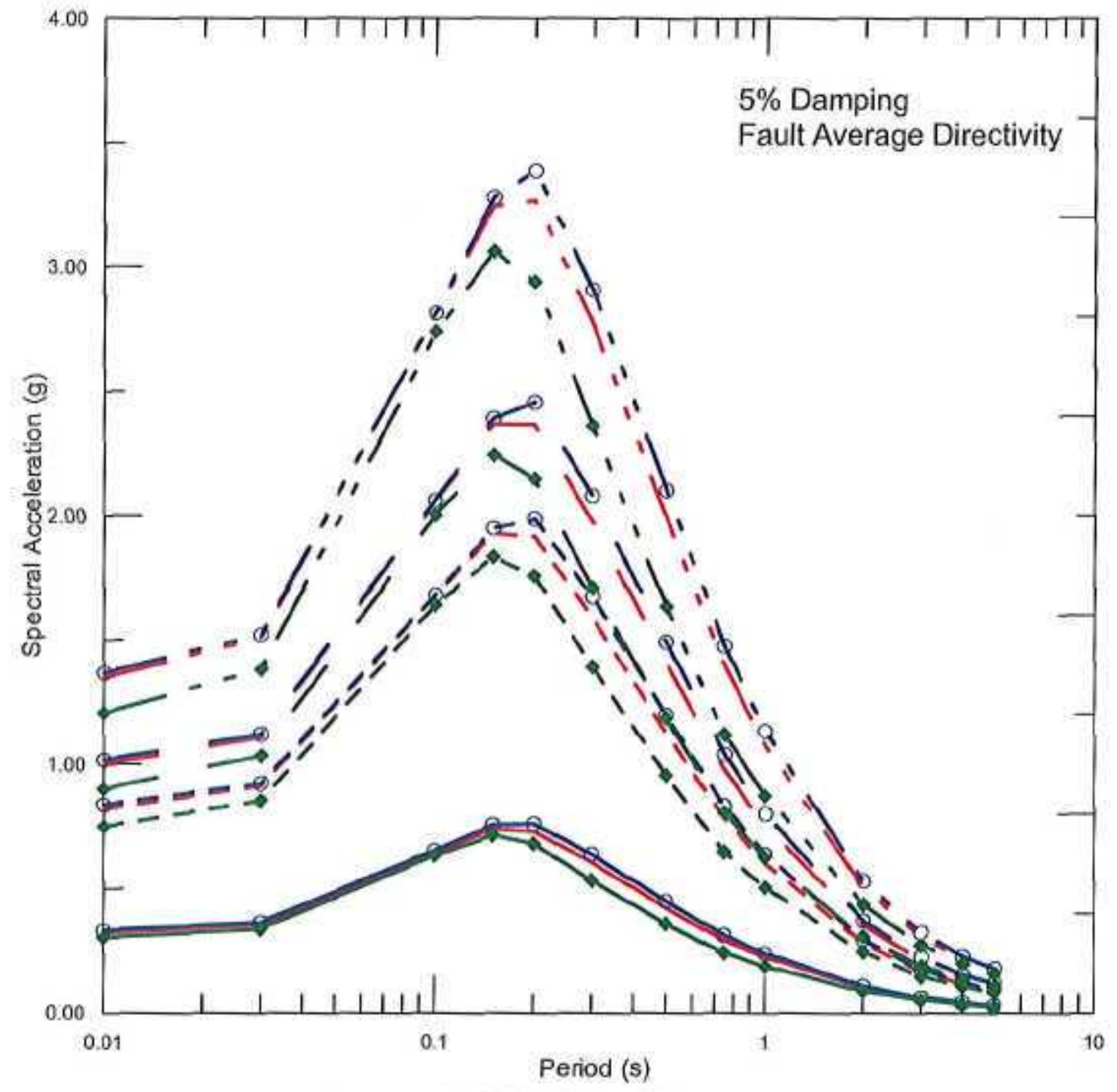

RETURN PERIOD

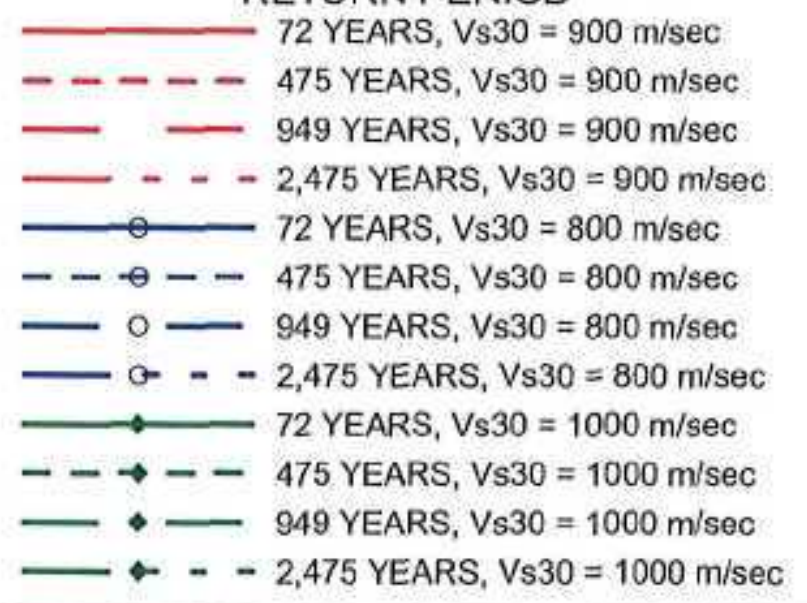




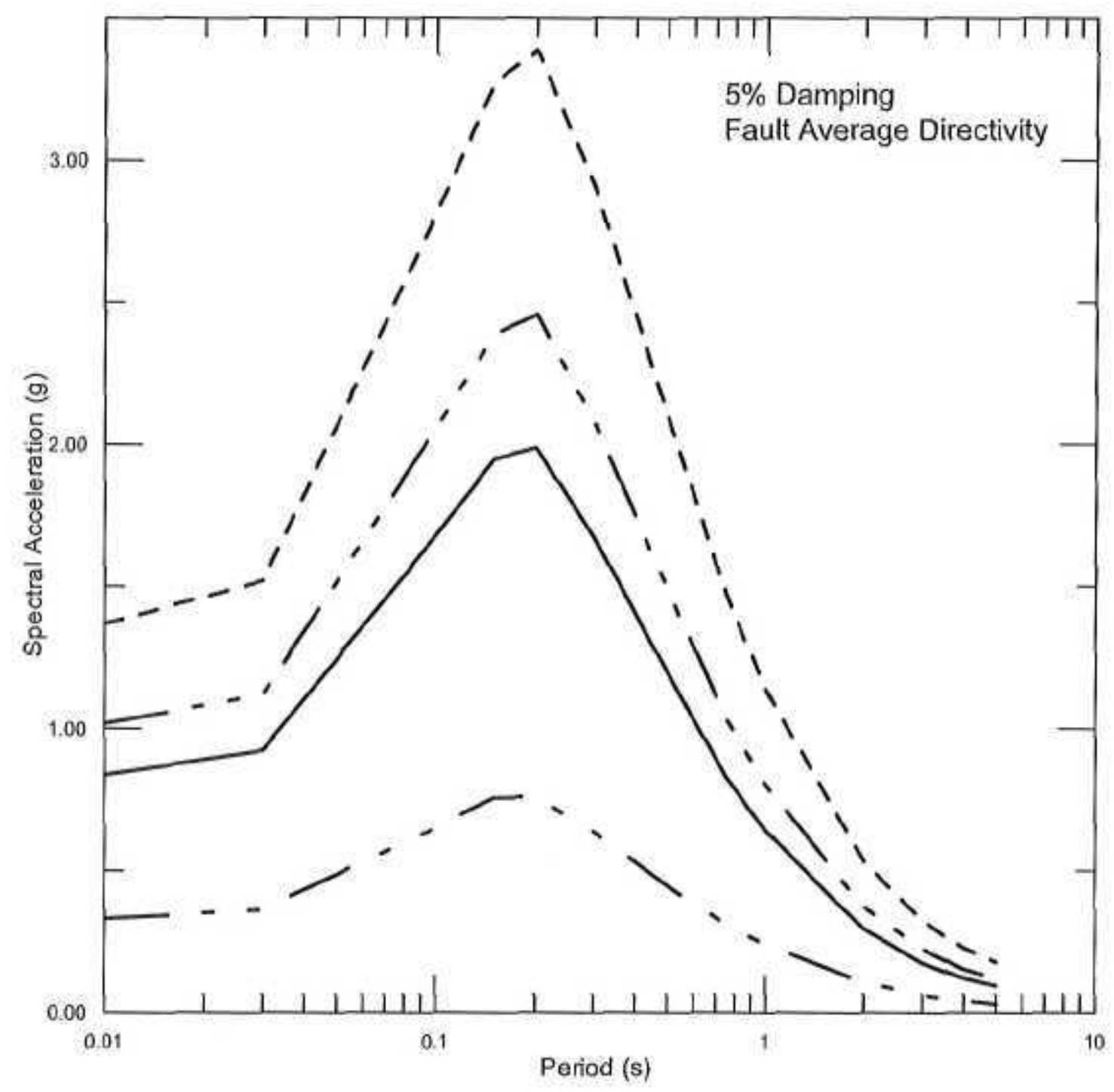

RETURN PERIOD

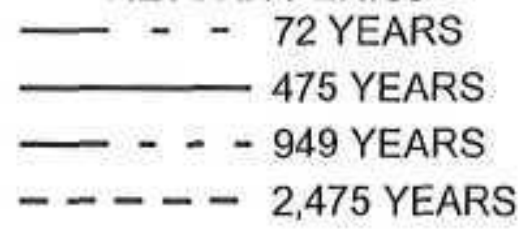




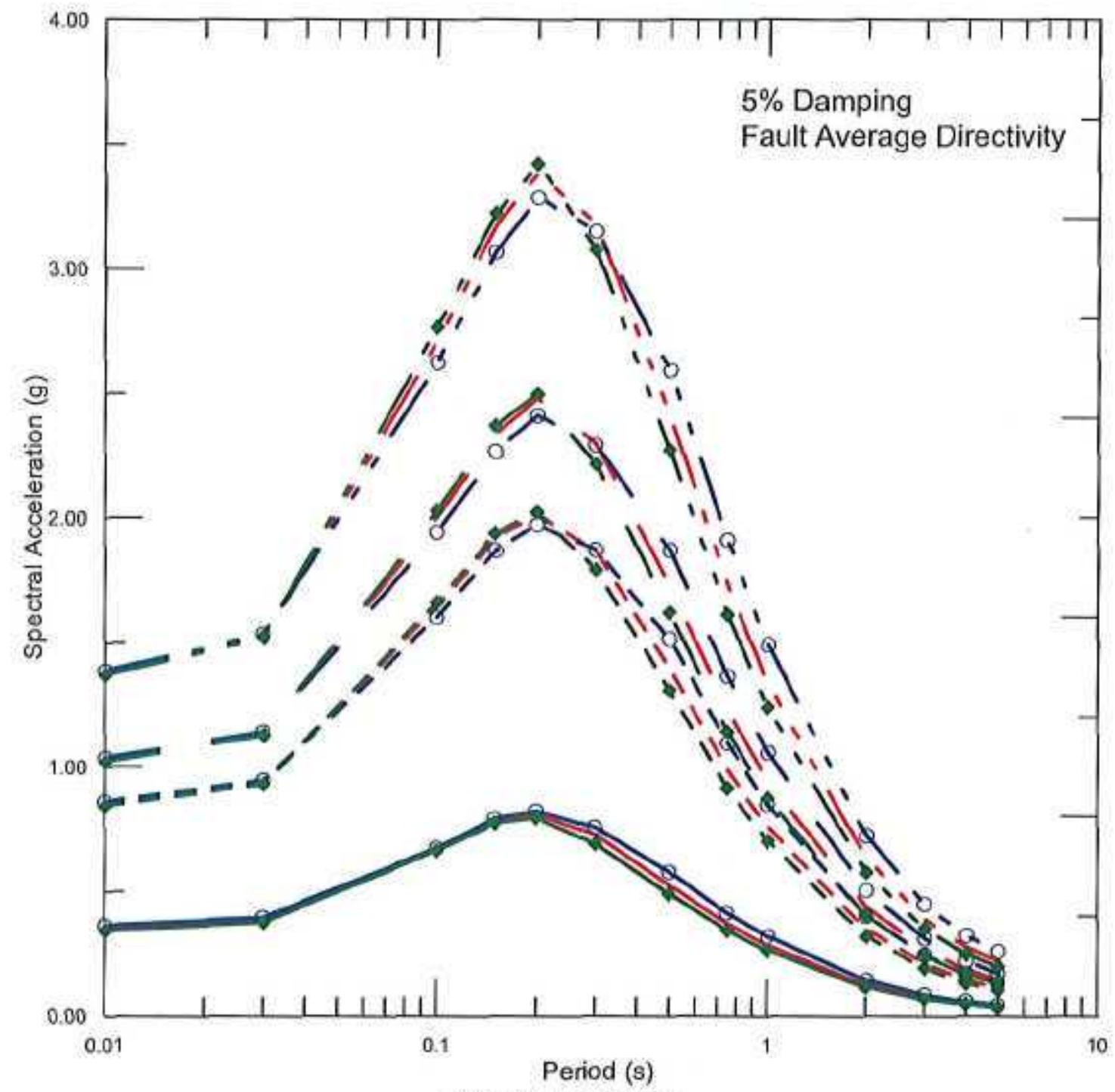

RETURN PERIOD

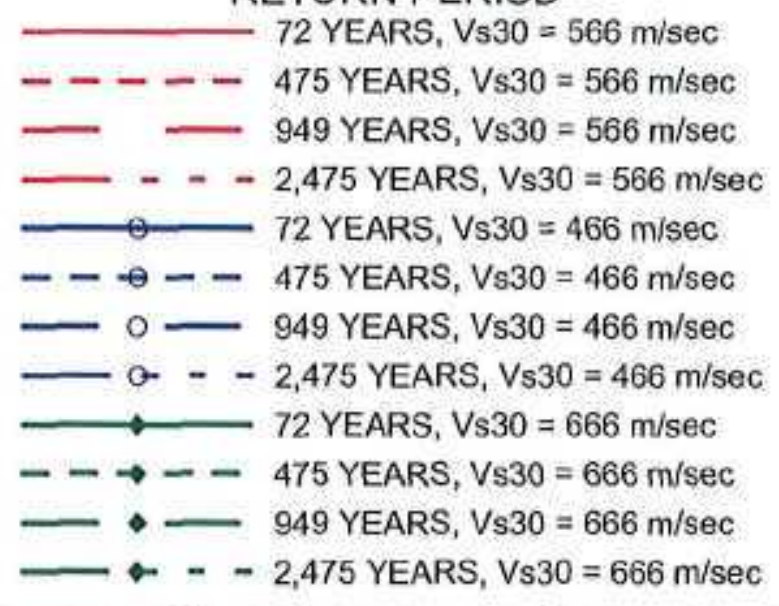




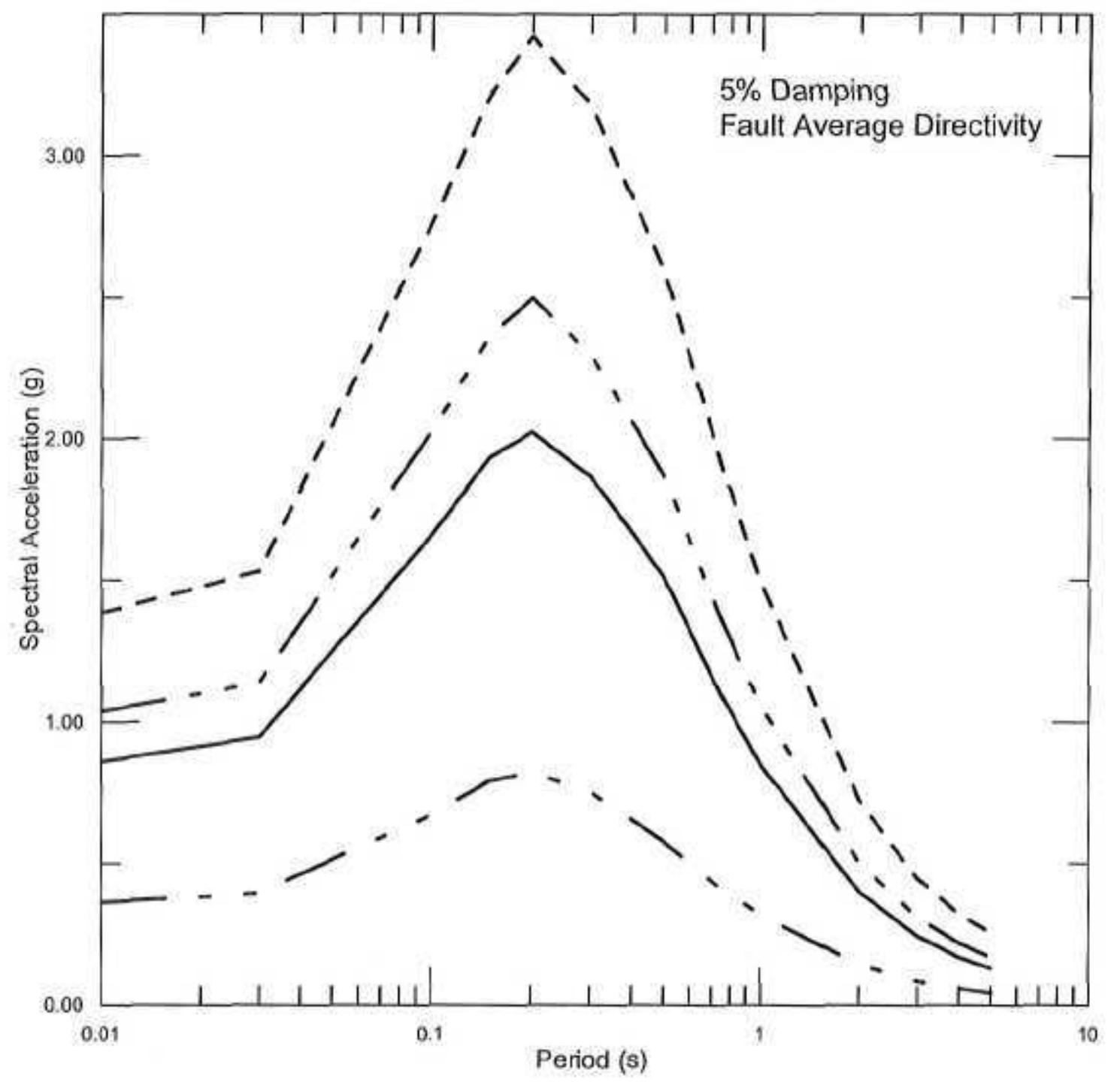

RETURN PERIOD

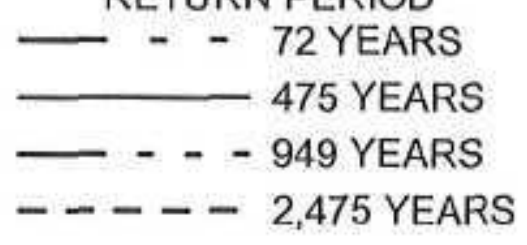



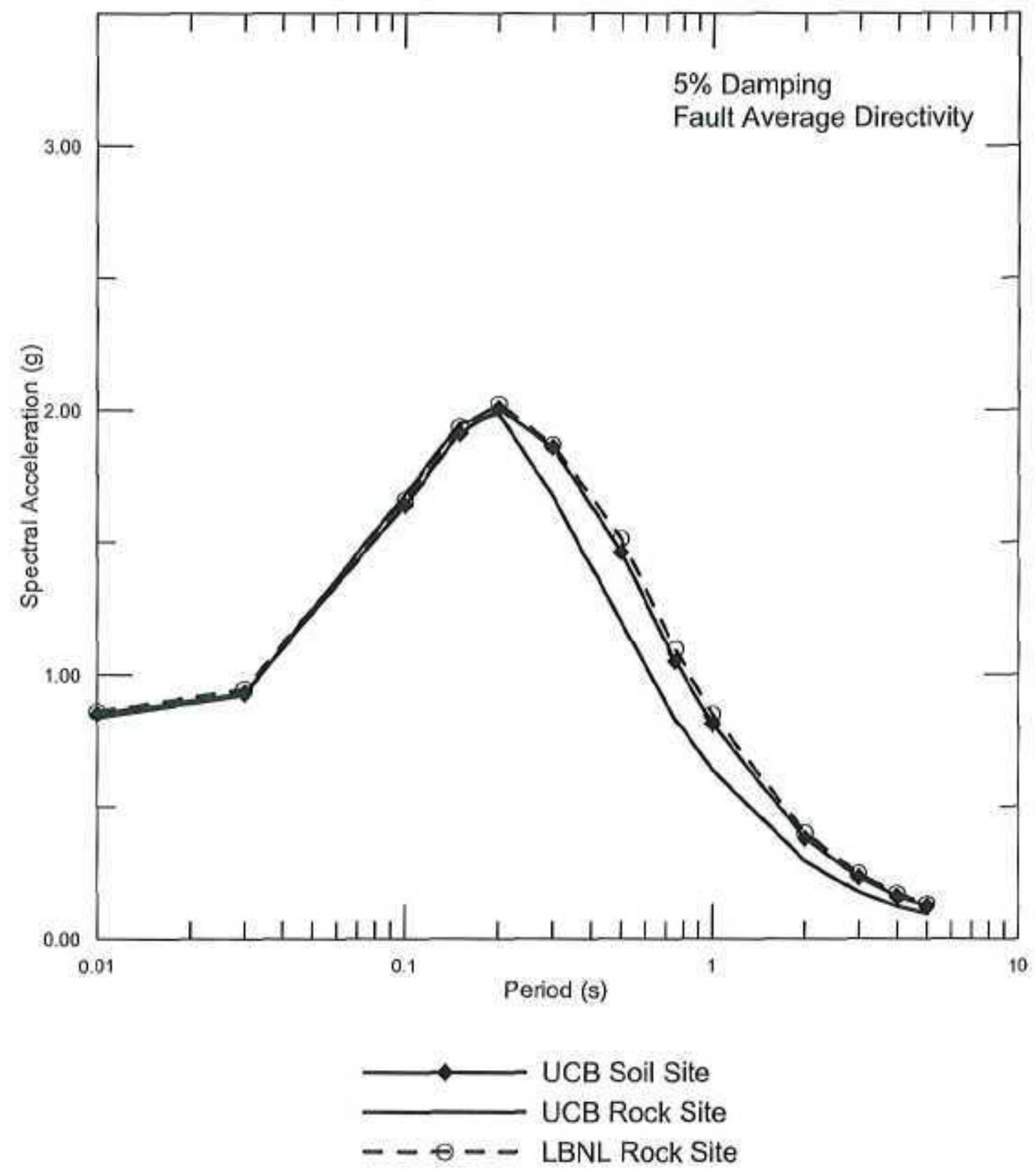


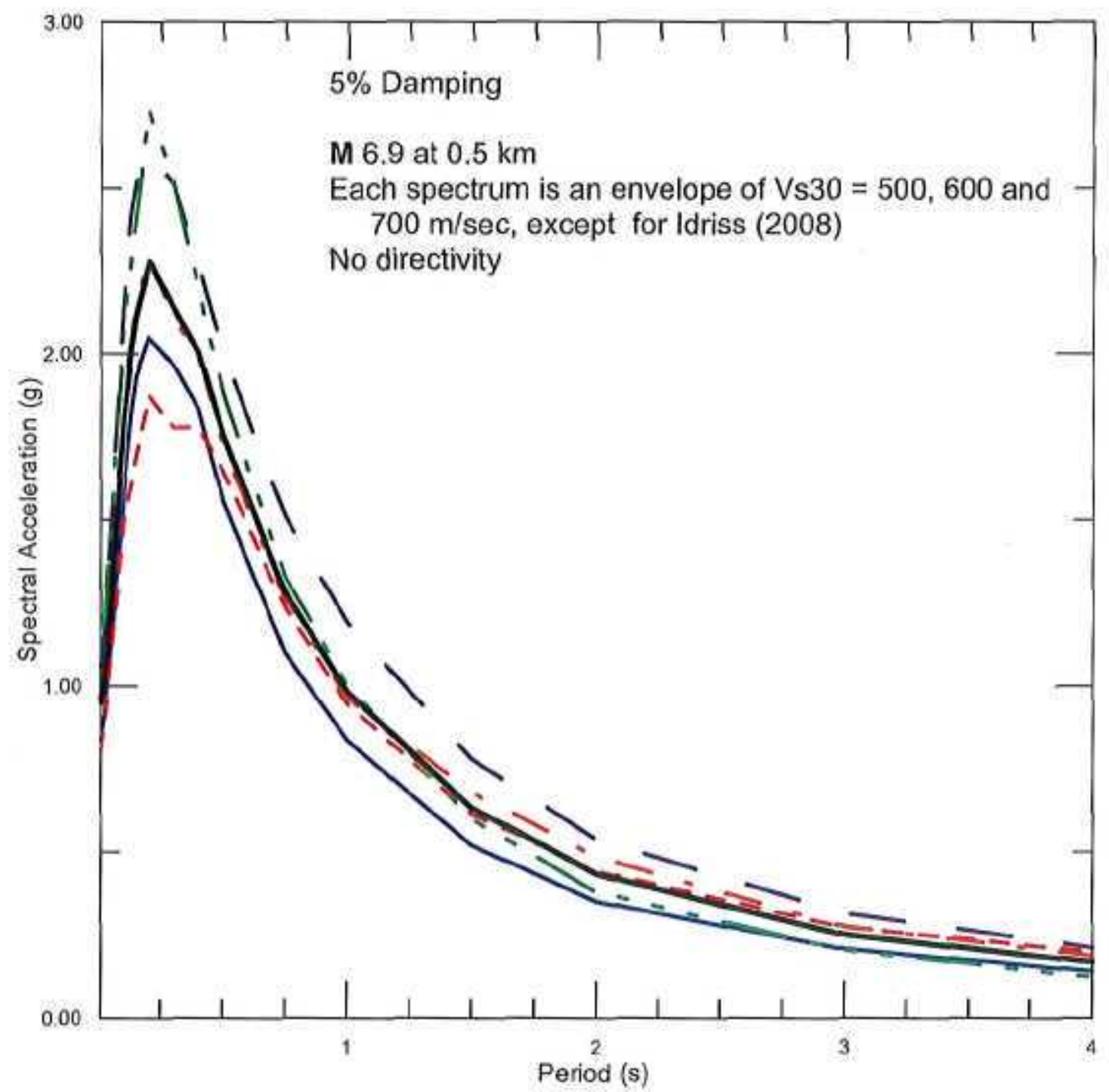

Wt. Average 84th Percentile Deterministic: M 6.9 at $0.5 \mathrm{~km}$

Abrahamson \& Silva (2008)

- - Boore \& Atkinson (2008)

- - - - Campbell and Bozorgnia (2008)

- Chiou and Youngs (2008)

— - - Idriss (2008) 


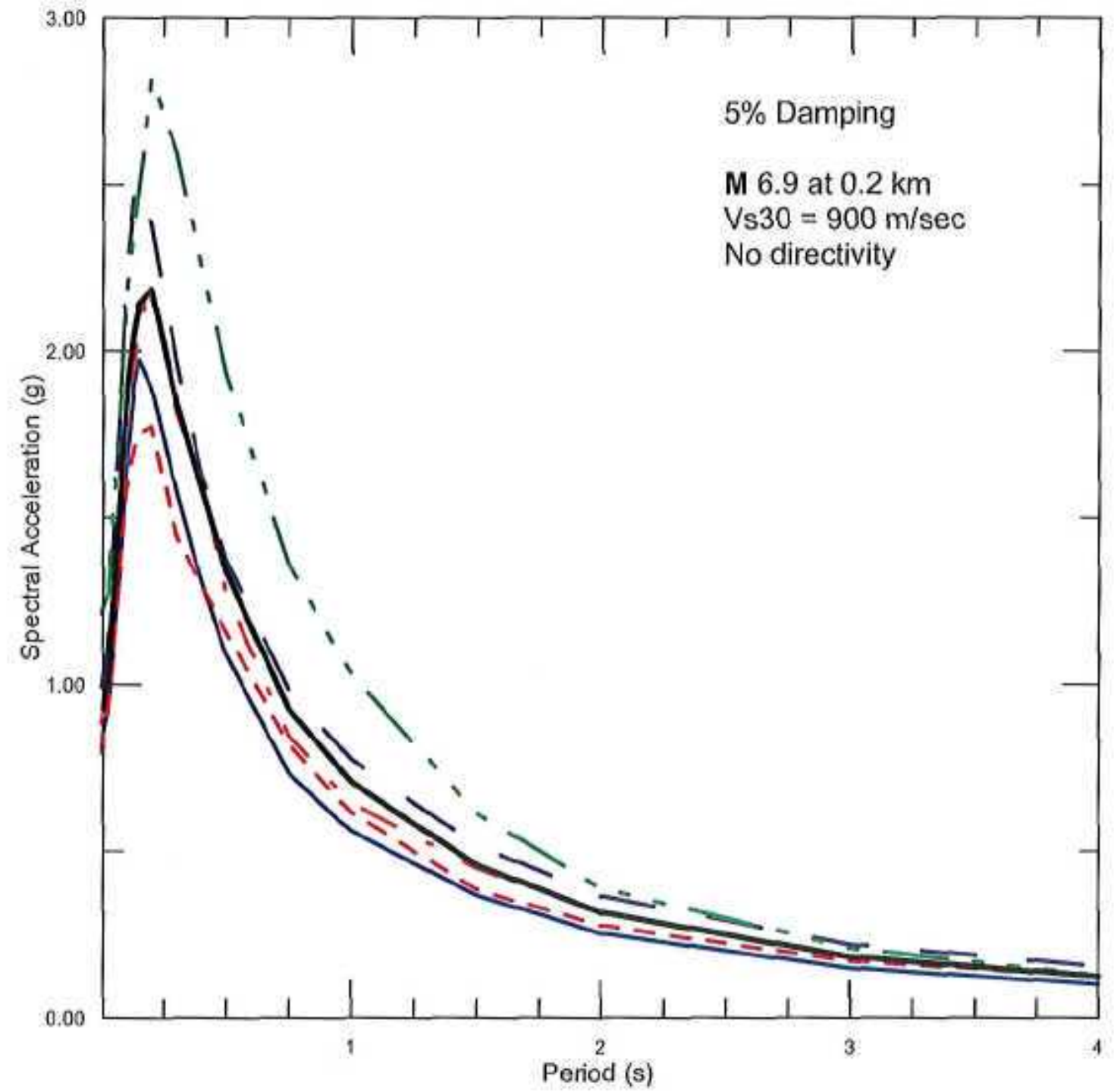

Wt. Average 84th Percentile Deterministic: M 6.9 at $0.2 \mathrm{~km}$ Abrahamson \& Silva (2008)

- - Boore \& Atkinson (2008)

- - - - - Campbell and Bozorgnia (2008)

- Chiou and Youngs (2008)

- - - Idriss (2008) 


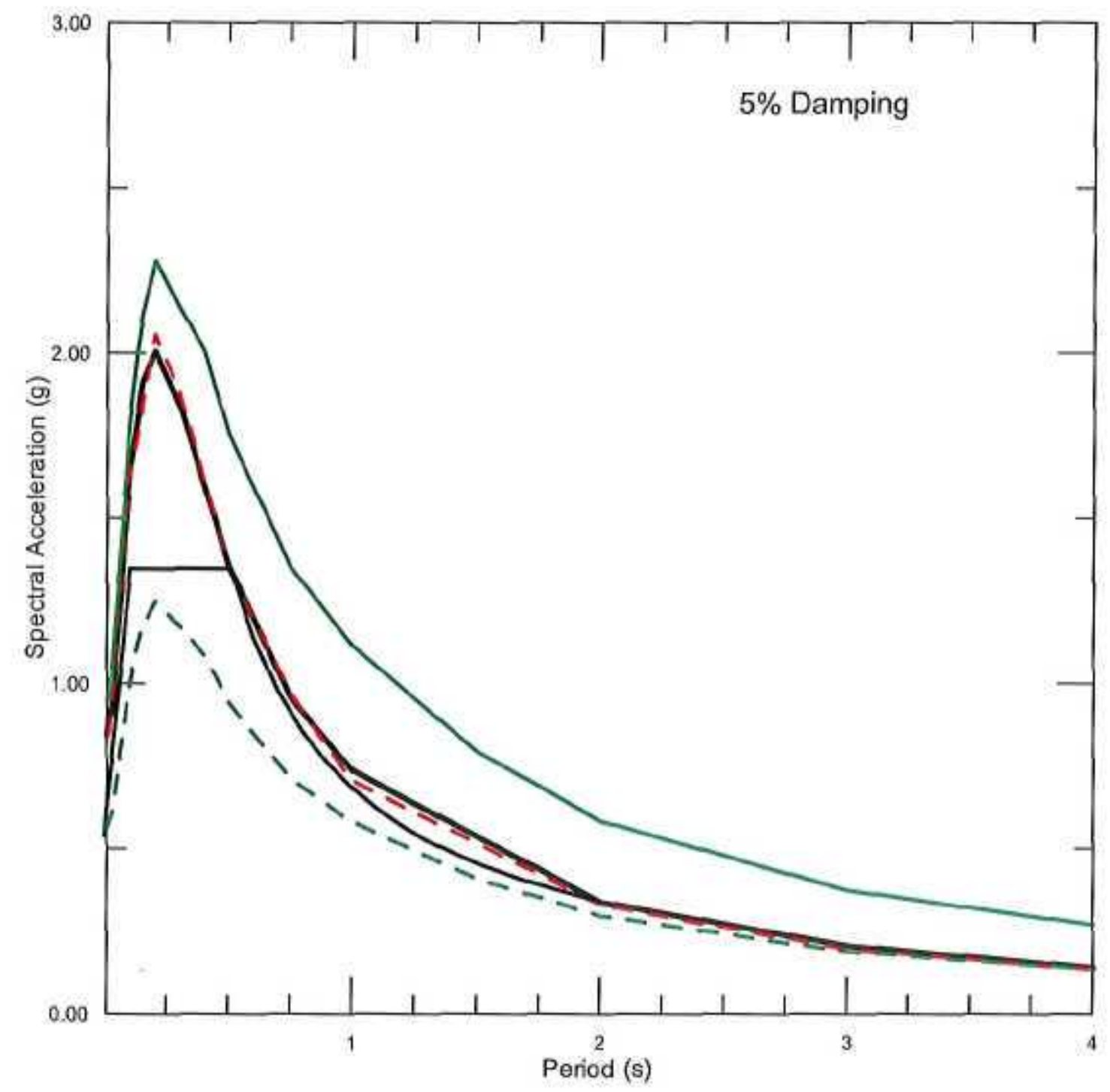

Current Study: 475-year UHS, Average Directivity, Soil Site

- _ - - 2003 Study: 475-year UHS, Average Directivity, Rock Site 2007 CBC Spectrum - Site Class C

- - - - Median Deterministic: M 6.9 at $0.5 \mathrm{~km}$, Average Directivity 84th Percentile Deterministic: M 6.9 at $0.5 \mathrm{~km}$, Average Directivity 


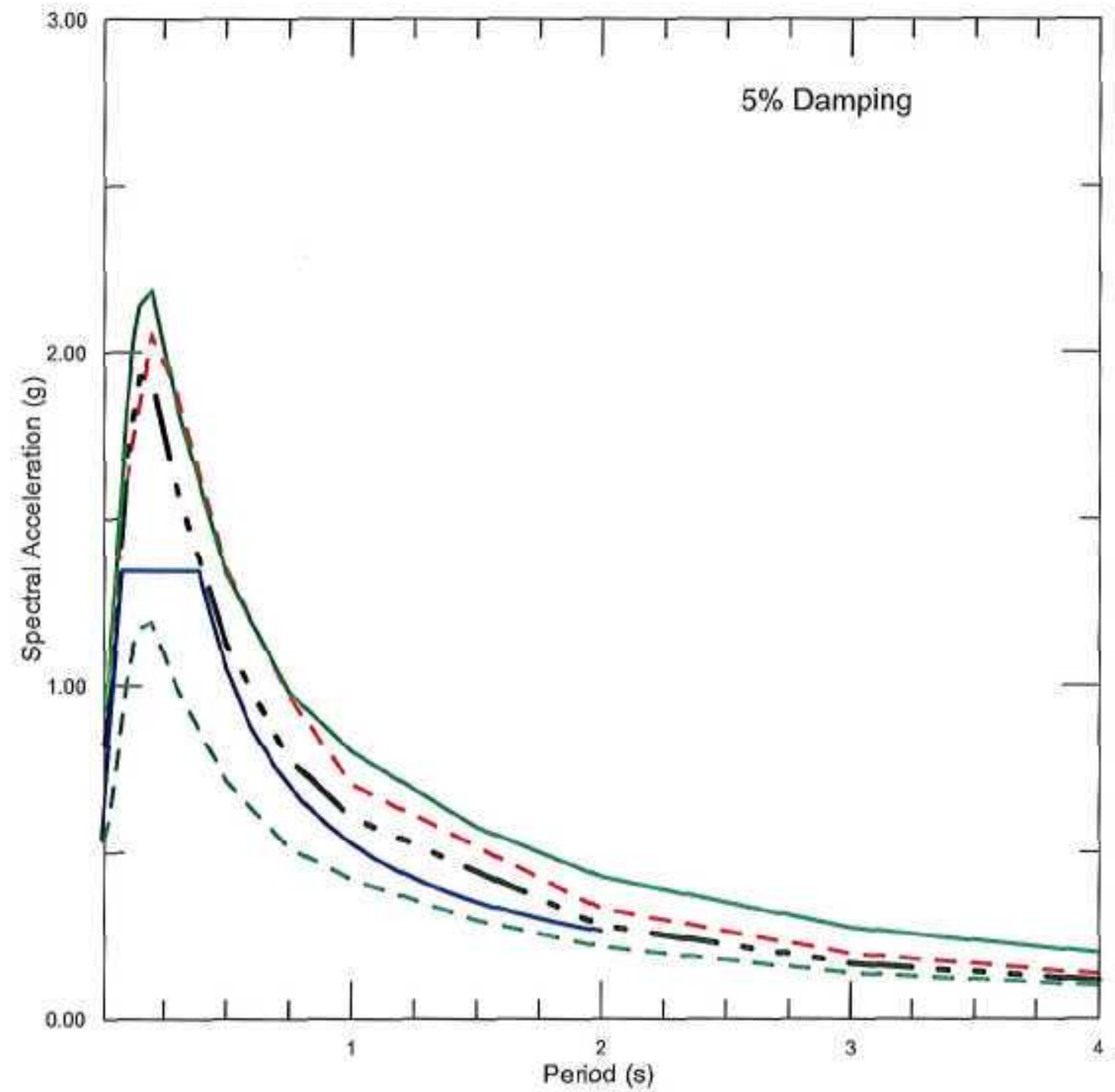

— - - - Current Study: 475-year UHS, Average Directivity, Rock Site

_ - _ - 2003 Study: 475-year UHS, Average Directivity, Rock Site 2007 CBC Spectrum - Site Class B

_ _ - Median Deterministic: M 6.9 at $0.2 \mathrm{~km}$, Average Directivity 84th Percentile Deterministic: M 6.9 at $0.2 \mathrm{~km}$, Average Directivity 